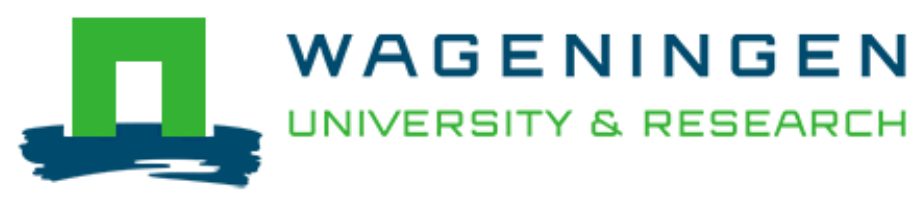

How social factors and behavioural strategies affect feeding and social interaction patterns in pigs

Boumans, I. J. M. M., de Boer, I. J. M., Hofstede, G. J., \& Bokkers, E.

This is a "Post-Print" accepted manuscript, which has been published in "Physiology and Behavior"

This version is distributed under a non-commercial no derivatives Creative Commons (c) (1) () $\Theta$ (CC-BY-NC-ND) user license, which permits use, distribution, and reproduction in any medium, provided the original work is properly cited and not used for commercial purposes. Further, the restriction applies that if you remix, transform, or build upon the material, you may not distribute the modified material.

Please cite this publication as follows:

Boumans, I. J. M. M., de Boer, I. J. M., Hofstede, G. J., \& Bokkers, E. (2018). How social factors and behavioural strategies affect feeding and social interaction patterns in pigs. Physiology and Behavior, 194, 23-40. DOI: 10.1016/j.physbeh.2018.04.032

You can download the published version at:

https://doi.org/10.1016/j.physbeh.2018.04.032 


\section{How social factors and behavioural strategies affect feeding and social interaction patterns in pigs}

Iris J.M.M. Boumans ${ }^{\mathrm{a}, 1}$, Imke J.M. de Boer ${ }^{\mathrm{a}}$, Gert Jan Hofstede ${ }^{\mathrm{b}}$ and Eddie A.M. Bokkers ${ }^{\mathrm{a}}$

${ }^{a}$ Animal Production Systems group, Wageningen University \& Research, P.O. Box 338, 6700 AH Wageningen, the Netherlands

${ }^{b}$ Information Technology group, Wageningen University \& Research, P.O. Box 8130, 6700 EW Wageningen, the Netherlands

\section{Abstract}

Animals living in groups compete for food resources and face food conflicts. These conflicts are affected by social factors (e.g. competition level) and behavioural strategies (e.g. avoidance). This study aimed to deepen our understanding of the complex interactions between social factors and behavioural strategies affecting feeding and social interaction patterns in animals. We focused on group-housed growing pigs, Sus scrofa, which typically face conflicts around the feeder, and of which patterns in various competitive environments (i.e. pig:feeder ratio) have been documented soundly. An agent-based model was developed to explore how interactions among social factors and behavioural strategies can affect various feeding and social interaction patterns differently under competitive situations. Model results show that pig and diet characteristics interact with group size and affect daily feeding patterns (e.g. feed intake and feeding time) and conflicts around the feeder. The level of competition can cause a turning point in feeding and social interaction patterns. Beyond a certain point of competition, meal-based (e.g. meal frequency) and social interaction patterns (e.g. displacements) are determined mainly by behavioural strategies. The average daily feeding time can be used to predict the group size at which this turning point occurs. Under the model's assumptions, social facilitation was relatively unimportant in the causation of behavioural patterns in pigs. To validate our model, simulated patterns were compared with empirical patterns in conventionally housed pigs. Similarities between empirical and model patterns support the model results. Our model can be used as a tool in further research for studying the effects of social factors and group

\footnotetext{
${ }^{1}$ Corresponding author. Tel. +31 3174838 82; e-mail: iris.boumans@wur.nl
} 
dynamics on individual variation in feeding and social interaction patterns in pigs, as well as in other animal species.

Keywords: competition; social facilitation; group dynamics; aggression; feed intake; animal welfare.

\section{Introduction}

Living in groups is associated with competition for food resources. Competition can be low if food is widely available and high if food is scarce or an easily defendable resource. Physiological factors, such as metabolic processes and hormonal circadian rhythms that promote or inhibit food intake in animals, can increase the popularity of certain times for feeding [1]. This can increase competition for food and the risk of conflicts between animals. Furthermore, social facilitation can stimulate animals to initiate or increase feeding if another animal is feeding [2], which can further increase the risk of conflicts.

In conflict situations, animals have various behavioural strategies to gain access to food. They can show offensive behaviour and enter (approach) conflicts around food resources or show defensive behaviour to avoid these conflicts. Approaching behaviour includes fights, in which individuals can force others to leave a food resource, whereas avoidance behaviour includes a delay in entering or retreating from a conflict for a food resource. The decision of an animal to approach or avoid a conflict is affected by various factors, such as the value of the resource, the costs of a fight and the likelihood of winning [3]. The physiological state of an animal can affect this decision. A hungry animal, for example, might value a food resource more and has a higher likelihood of winning a fight for access than a less hungry animal [see review 4]. Moreover, the probability of a fight can increase when individuals have more equal chances of winning a fight (e.g. small dominance difference) and when the benefit of winning is high compared to the cost of losing a fight [5].

Variation in behavioural strategies of individuals in response to conflicts can lead to different individual feeding and social interaction patterns, such as feeding at desirable or less desirable times, more or fewer (aggressive) interactions, and feeding more or less frequently. The relation between 
these feeding and social interaction patterns with behavioural strategies and social factors, such as competition and social facilitation, however, is not fully understood. Understanding the mechanisms underlying behavioural patterns is of interest because it can provide insight into the variation of these patterns and the ability of animals to adapt to competitive situations. This is especially relevant for group-living domestic animals, which are not able to leave a group and have to deal with conflicts. These animals are often fed at a single location and at specific times, which can increase competition and defensive behaviour, resulting in high stress and aggression levels [6, 7]. Improved knowledge about competition for food and its effect on behavioural patterns can help in preventing aggression, stress and reduced feed intake in these animals.

Optimizing performance and preventing aggression in farm animals receives much attention in research [e.g. 8, 9, 10]. Empirical studies, however, often show inconsistent results in performance and aggression and it is unclear how social factors and group dynamics affect these results [11]. Agent-based modelling can help to increase understanding of potential factors influencing behavioural patterns in animals. This modelling method lends itself particularly well for modelling group dynamics underlying behavioural patterns [12]. Agent-based modelling allows the inclusion of social interactions, individual variation and time dependent factors. Furthermore, it makes it possible to test the effect of these factors in various combinations and ranges, without the limitations of empirical studies associated with costs and use of many animals [13].

The aim of this study was to deepen our understanding of the complex interactions between social factors and behavioural strategies affecting feeding and social interaction patterns in animals by using an agent-based model (ABM) (Fig. 1). We focus in this study on pigs, Sus scrofa. Pigs are a typical example of animals that are often housed in fixed group sizes with one feeding place. Group size, and consequently pig:feeder ratio, can reduce accessibility to a feeding place for pigs, and therefore, increase competition and affect feeding behaviour [14]. An advantage of using domestic animals as subjects compared to wild conspecifics, is that they are suggested to have similar 
behavioural responses and decision-making abilities, while empirical data on their behaviour are replicable, available in larger sample sizes and less affected by confounding factors such as weather conditions or food resource differences [15].

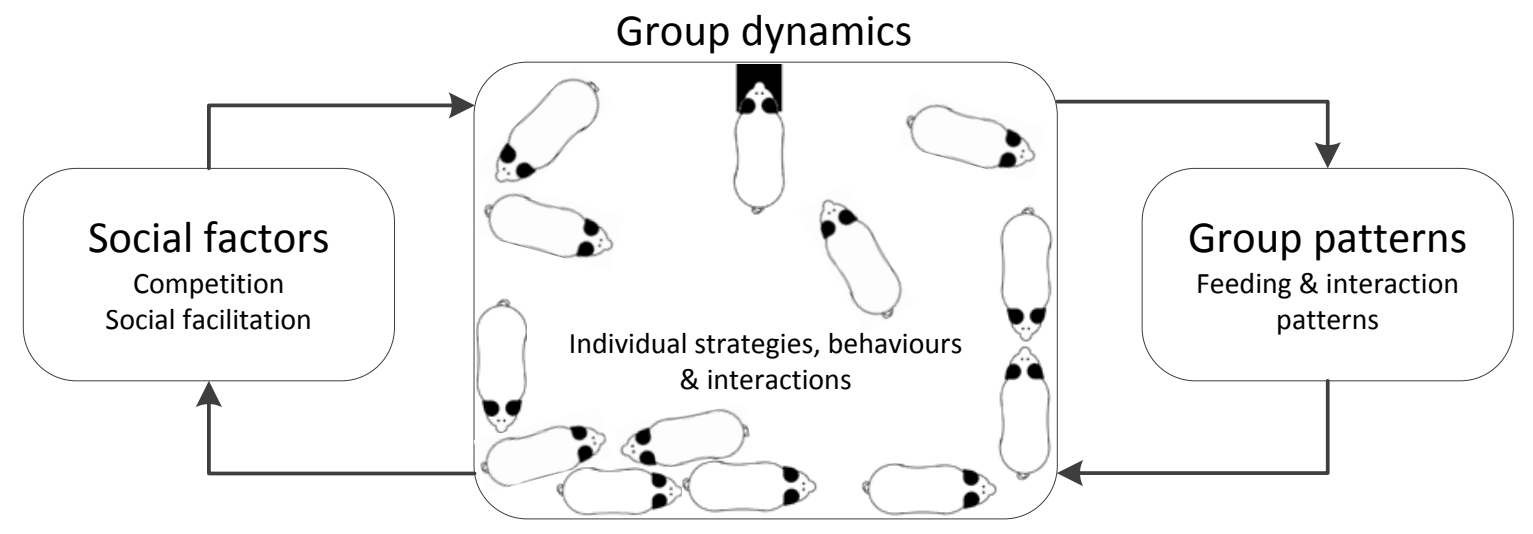

Fig. 1. Visual representation of social factors, group dynamics and behavioural group patterns in pigs included in the agent-based model

We carried out a literature study on the development of feeding and interaction behaviour of conventionally housed growing pigs in empirical studies. Based on that study, we developed an ABM that simulates this behaviour under varying pig:feeder ratios. Pigs (agents) in the model are individually programmed and make behavioural decisions based on their own motivations and interactions with pen mates. This model builds on our previous modelling work on (1) metabolic and growth processes underlying feeding patterns during the growth period of a pig (Boumans et al., 2015 [16]), and (2) interaction between metabolic processes and hormonal circadian rhythms during a 24 hour period (Boumans et al., 2017 [17]). This ensures that in the current model, which focusses on social interactions and competition, the other elements of the pigs' behaviour, for example their hormone levels or nutritional needs, are based on first principles and have been tested separately. The model simulates effects of physiological factors, social factors and behavioural strategies on individual behaviour. This allows exploring the effect of interaction between these aspects on emergent feeding and social interaction patterns of group-housed pigs. In this paper, we first present a theoretical framework, including an overview of empirical feeding and social interaction patterns of 
pigs in literature and hypotheses about underlying mechanisms. Subsequently, we describe the developed $A B M$ to test these hypotheses, analyse the model results, and discuss the findings.

\subsection{Theoretical framework on feeding \& social interaction patterns in pigs}

A theoretical framework was constructed using pattern-oriented modelling (POM), which is a strategy to characterise the system of interest through different scales and organisational levels [18, 19]. A model that simultaneously simulates various patterns similar to identified empirical patterns is expected to encompass accurate mechanisms and to be more robust in model structure and parameterisation. Based on a literature study, various empirical feeding and social interaction patterns were identified and used to design the model. These patterns and hypothesised underlying mechanisms are described in this section.

\subsubsection{Feeding patterns}

Feeding patterns of growing and finishing pigs with access to one feeding space (that allows one pig to feed at any time) have been studied in various group sizes (Table 1). Feeding patterns observed in these studies varied (Fig. 2), which can be a result of many factors, such as diet characteristics and breed. To avoid having to deal with these various confounding factors, our study focused mainly on the variation in feeding patters between group sizes within studies, and less on the variation in patterns between studies. Feeding patterns between group sizes show some general trends. Feed intake (g/day) remains relatively similar in all group sizes in the same study. While feeding time (min/day) decreases, feeding rate $(\mathrm{g} / \mathrm{min})$ increases with increasing group size. Meal size (g/meal/day) mainly increases in larger groups, whereas meal frequency (no/day) shows exactly an opposite pattern. Meal duration ( $\mathrm{min} / \mathrm{meal} /$ day) shows a pattern similar to meal size, except for the study of Walker [20], in which meal duration decreases with larger groups.

The meal-based feeding patterns (meal frequency, meal duration and meal size) seem to have a turning point around a group size of 4 to 8 [21], 8 [22] and around 10 to 15 pigs [23], after which 
meal patterns change direction (Fig. 2). The variation in turning point can be caused by factors, such as space availability and body weight in the specific studies. 

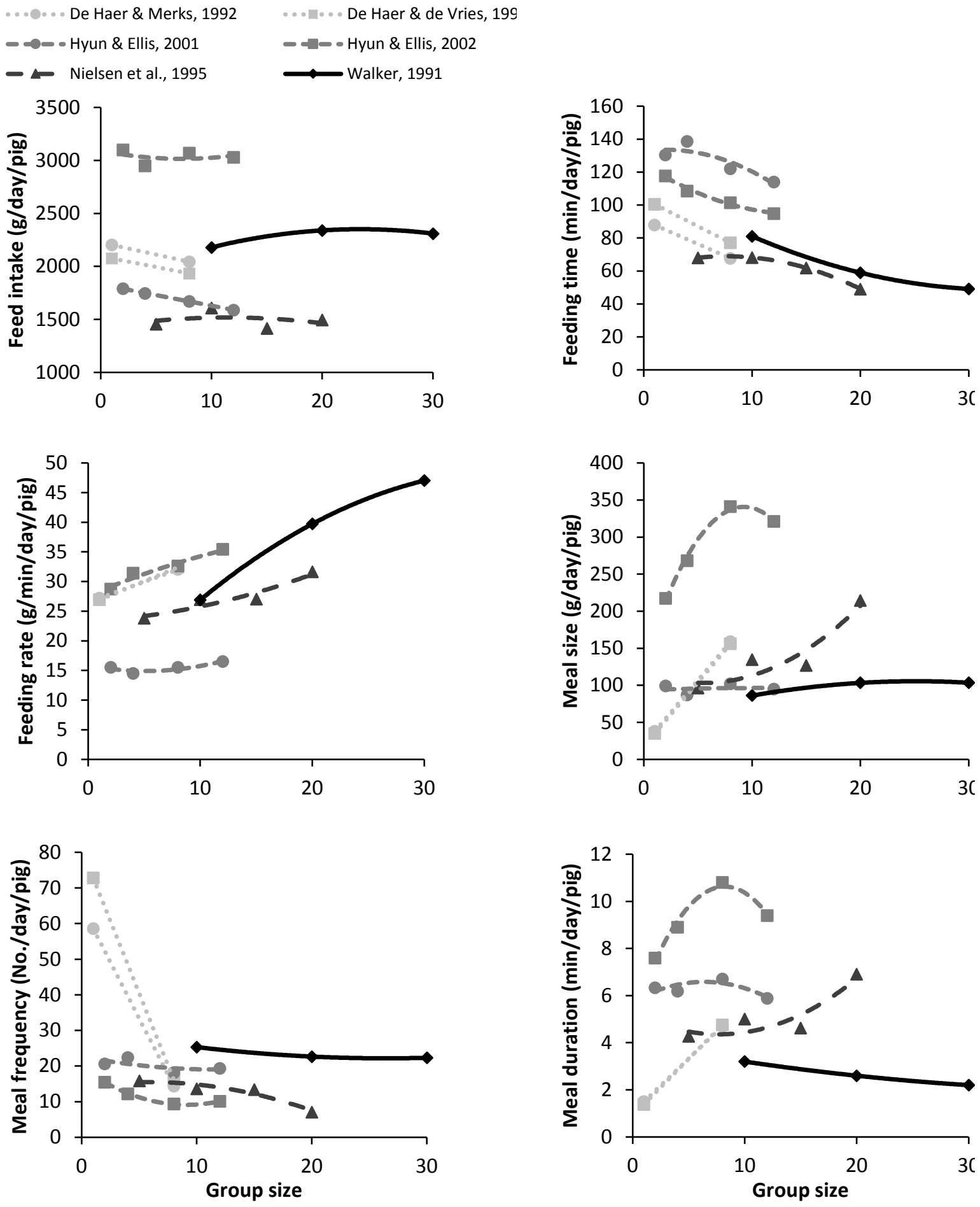

Fig. 2. Feeding patterns of growing and finishing pigs in various group sizes and studies. A polynomial trend line is drawn through data points from empirical studies for illustrative purposes. Details on the corresponding studies are listed in Table 1. 
Table 1. Characteristics of studies that observed feeding patterns in growing and finishing pigs in various group sizes with one single space feeder and ad libitum access to feed.

\begin{tabular}{|c|c|c|c|c|c|c|c|}
\hline Study & $\begin{array}{l}\text { Feeding } \\
\text { system }\end{array}$ & $\begin{array}{l}\text { Diet } \\
\text { characteristics }\end{array}$ & $\begin{array}{l}\text { Group } \\
\text { size }\end{array}$ & $\begin{array}{l}\quad \text { Body } \\
\text { weight } \\
\text { range } \\
(\mathrm{kg})\end{array}$ & Breed & $\begin{array}{l}\text { Floor } \\
\text { space } \\
\text { (m²/pig) }\end{array}$ & Sex \\
\hline $\begin{array}{l}\text { De Haer \& } \\
\text { Merks, } 1992\end{array}$ & $\begin{array}{l}\text { Electronic } \\
\text { feeder (IVOG) }\end{array}$ & $\begin{array}{l}\text { Type unknown, } \\
9.4-9.1 \mathrm{MJ} \text { NE/kg1 }\end{array}$ & 1,8 & $25-100$ & $\begin{array}{l}\text { Dutch } \\
\text { Landrace }\end{array}$ & $\begin{array}{l}3.27^{2} \\
0.76^{3}\end{array}$ & Males \\
\hline $\begin{array}{l}\text { De Haer \& } \\
\text { de Vries, } \\
1993\end{array}$ & $\begin{array}{l}\text { Electronic } \\
\text { feeder (IVOG) }\end{array}$ & $\begin{array}{l}\text { Type unknown, } \\
9.4-9.1 \mathrm{MJ} \text { NE/kg1 }\end{array}$ & 1,8 & $25-100$ & $\begin{array}{l}\text { Dutch } \\
\text { Landrace }\end{array}$ & Unknown & $\begin{array}{l}\text { Males and } \\
\text { females } \\
\text { separated }\end{array}$ \\
\hline $\begin{array}{l}\text { Hyun \& Ellis, } \\
2001\end{array}$ & $\begin{array}{l}\text { Electronic } \\
\text { feeder (FIRE) }\end{array}$ & $\begin{array}{l}\text { Meal-based', } \\
13.8 \text { kJ ME/kg } 5\end{array}$ & $2,4,8,12$ & $27-48$ & Crossbred 6 & 0.9 & Mixed \\
\hline $\begin{array}{l}\text { Hyun \& Ellis, } \\
2002\end{array}$ & $\begin{array}{l}\text { Electronic } \\
\text { feeder (FIRE) }\end{array}$ & $\begin{array}{l}\text { Meal-based }{ }^{4}, \\
13.9 \mathrm{MJ} \mathrm{ME} / \mathrm{kg}^{5}\end{array}$ & $2,4,8,12$ & $84-113$ & Crossbred $^{6}$ & 0.9 & Mixed \\
\hline $\begin{array}{l}\text { Nielsen et } \\
\text { al., } 1995\end{array}$ & $\begin{array}{l}\text { Electronic } \\
\text { feeder (FIRE) }\end{array}$ & $\begin{array}{l}\text { Pellet-based }{ }^{4}, \\
\text { 13.4 MJ DE/kg7 }\end{array}$ & $5,10,15,20$ & $34-56$ & Crossbred $^{8}$ & 1.06 & Males \\
\hline $\begin{array}{l}\text { Walker, } \\
1991\end{array}$ & $\begin{array}{l}\text { Single space } \\
\text { wet \& dry } \\
\text { feeder }\end{array}$ & $\begin{array}{l}\text { Meal-based }{ }^{4}, \\
\text { 13.4 MJ DE/kg7 }\end{array}$ & $10,20,30$ & $37-90$ & Crossbred $^{8}$ & 0.6 & Mixed \\
\hline
\end{tabular}

\footnotetext{
${ }^{1}$ Starter and final diet in Netto energy (NE), ${ }^{2}$ Individually housed, ${ }^{3}$ Group-housed, ${ }^{4}$ Meal-based = loose compound feed particles, pellet-based $=$ compressed compound feed particles, ${ }^{5} \mathrm{ME}=$ Metabolisable energy, ${ }^{6} \mathrm{PIC}$ Line $26 \times$ Camborough $15,{ }^{7} \mathrm{DE}=$ Digestible energy, ${ }^{8}$ Large White $\mathrm{x}$ Landrace
}

\subsubsection{Circadian distribution of feeding patterns}

In both individually and group housed pigs, feed intake is usually observed in an alternans pattern, with a low level of feed intake during night and two peaks during day, with the highest peak being the second one [e.g. 23, 24]. The distribution of feed intake during day time is more equal in individually housed pigs than in group housed pigs [24]. Pigs in small groups occupy the feeder mostly around the peak times, although these peaks merge in the larger groups (Fig. 3). In all studies, feeder occupation increases with group size during day and night, although pigs in the largest groups proportionally feed more during night than pigs in the smaller groups [21,23]. Feeder occupation per hour is mostly less than $100 \%$, even during peak times, except for the largest groups (group size 12 and 30 respectively in the studies of Walker [20], Hyun and Ellis [21]), which fully occupy the feeder during day time and more than $60 \%$ during night time. 


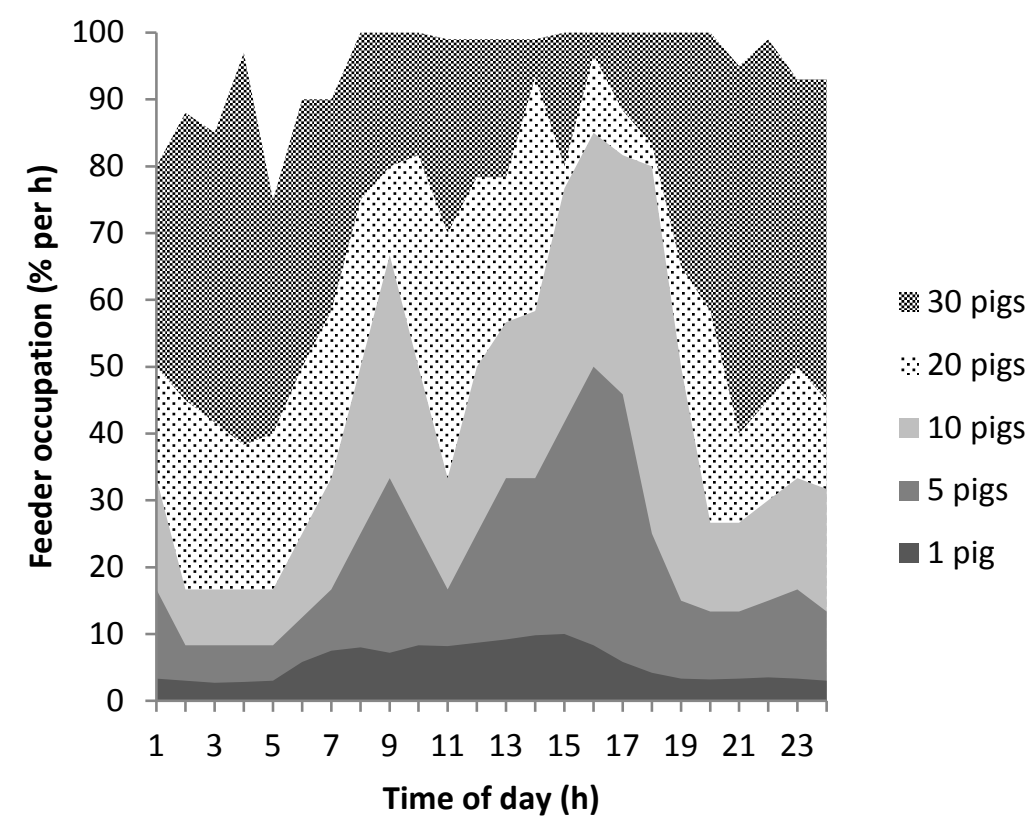

Fig. 3. Distribution of feeder occupation by pigs (\% per $\mathrm{h}$ ) during the day in various group sizes. Based on data from individually housed pigs [24], group size 5, 10 and 20 [23], and group size 30 [20].

\subsubsection{Social interaction patterns around feeding}

In group housing, pigs can approach a pen mate at the feeder and (try to) displace it. Nielsen et al. [23] found that displacements attempts on day 28 increased from 0.37 attempts per pig per $\mathrm{h}$ in group size 5 to 1.25 attempts per pig per $\mathrm{h}$ in group size 20 , whereas the success rate of attempts decreased from $37.9 \%$ in size 5 to $7.1 \%$ in size 20 . Neither the attempts nor the success rates, however, were significantly different. Hyun and Ellis [21] observed a significantly higher number of forced exits from the feeder in group sizes 8 (18,8\% of observations) and 12 (32.8\% of observations) compared to group sizes 2 and 4 (5\% of observations). In addition, Walker [20] found the number of pigs queuing (standing or lying and facing the feeder when the feeder was occupied) increased significantly from on average 0.9 pigs in group size 10 to 1.9 pigs in group size 30 . Thus, displacements at the feeder seem to occur occasionally, and can occur more frequently in larger groups where the feeder is occupied most of the time. 


\subsection{Hypothesised underlying mechanisms}

We hypothesise that interaction between physiological factors, social factors and behavioural strategies can explain the observed feeding and social interaction patterns in pigs. Our hypothesis is further explained below.

\subsubsection{Physiological factors}

Physiological factors, such as metabolic processes and hormonal circadian rhythms, affect feeding motivation during the day. These factors explain the typical feeding patterns with a low level of feed intake during night and two peaks during day in individually housed pigs [17]. We hypothesise that increased feeding motivation due to circadian rhythms in physiological factors increases competition at specific times among group-housed pigs. Furthermore, feeding motivation is likely to influence the decision for a behavioural strategy of an individual.

\subsubsection{Social factors and behavioural strategies}

Social facilitation and competition are expected to affect the probability of interactions between pigs and the initiation and termination of feeding behaviour. Social facilitation can increase the probability that pigs want to feed simultaneously and increase competition. The effect of competition on behaviour depends on the behavioural strategy of an individual towards a conflict. Pigs can avoid aggressive behaviour, for example, by waiting to feed till the feeder is available, which can be at less desirable times [25]. Avoidance behaviour can explain, for example, why pigs feed proportionally more at night in larger groups [e.g. 21, 22, 23], even though feeders are rarely fully occupied during assumedly more desired peak times. Avoidance behaviour will prevent interactions and can delay feeding initiation, whereas approaching will cause interactions and can accelerate feeding termination if a feeding pig is displaced from the feeder or delay feeding initiation if the displacement attempt was unsuccessful. Thus competition can explain increased interactions, a decrease in meal frequency by avoidance and unsuccessful displacement attempts, and a decrease in meal duration by successful displacement attempts. 
We hypothesise that in response to more competition in larger groups, an increase in the incidence of avoidance strategies explains the empirically observed increase in meal duration and decrease in meal frequency in pigs, whereas an increase in the incidence of approach strategies explains opposite patterns. This would explain why meal-based feeding patterns can change direction from a certain group size onwards. Because feeding patterns are interrelated [26], a change in meal frequency or meal duration will also affect the other feeding patterns. When meal frequency decreases, for example, meal size needs to increase to reach the same amount of daily feed intake.

\section{Model description}

A two dimensional ABM was constructed and implemented in the program Netlogo [27], version 5.3.0. The model simulates social interactions and feeding behaviour of individually and grouphoused pigs. The model was built and validated in three steps. In the first step, daily feeding patterns of an individually housed pig during the entire growing/fattening period were modelled based on metabolic factors (processing of feed and energy balance) and growth factors (energy use for maintenance, activity and protein and fat deposition) [see 16 for detailed explanation]. In the second step, hormonal circadian rhythms were included to model feeding patterns within a day (24 h) [17]. In that model, feeding patterns of an individually housed pig were affected by internal physiological factors, such as energy absorption, use and requirement [see 17 for detailed explanation]. The present paper presents the third step in which multiple pigs and social factors were included in the model. While the previous model explained how internal factors motivate a pig to feed, the current model shows how the social context affects feeding and social interaction patterns. During model development, the previous model was used 1:1 and extended with new variables each step (see Appendix A for use of variables in the current and previous models). If changes were made to an earlier version model, this were minor changes to improve processes due to new insights. The current model and a detailed model description following the ODD (Overview, Design concepts, Detail) protocol $[28,29]$ can be downloaded from the model library on the CoMSES website [30]. 


\subsection{Model environment and agents}

The simulation environment represents a conventional pig housing with a barren pen containing a concrete floor. The housing provides ad libitum access to feed, via one feeding place, containing a commercial diet that meets the requirements of a growing pig. The feeding place is an assigned area that allows one pig to feed at any time. Other behaviours (exploring, drinking, standing and lying) can be performed simultaneously by multiple pigs.

The agents represent growing pigs with individual characteristics such as sex (female, male or castrated male), body weight, growth potential and dominance level. In the standard setting of the model, pigs represent females and start with an body weight of $28 \mathrm{~kg}$. Growth potential of pigs depends on the mean body protein deposition and sex-related growth curve [see 16 for detailed explanation]. Due to randomisation of potential body protein deposition (based on a normal distribution with the mean corresponding to the mean body protein deposition and a $10 \%$ standard deviation) and emerging behavioural patterns and energy use, body weight can diverge among pigs in a pen. At set up of each simulation, pigs are randomly assigned a fixed dominance value that represents their hierarchical position in the group assuming a linear hierarchy. Lower dominance values represent a lower hierarchical position, such that the pig with value one is lowest in rank, followed by two, three, etc. An overview of state variables and values in the model can be found in the Appendix A, Table A1.

One time step in the model represents one minute, so that 1440 minutes represent one day. Minutes are associated with time of the day and light and dark periods. Simulations can run to represent the whole growing period of a pig (of about 120 days).

\subsection{Model processes}

The decision-making process of a pig per time step consists of three parts: "Update motivations", "Select behaviour" and "Growth" (Fig. 4). The included mechanisms are further explained below. 


\subsubsection{Update motivations}

Agents update their motivations for feeding, exploring, drinking or lying behaviour each minute. Each motivation is based on a drive and a threshold. The drive represents an internal build-up of energy to perform a certain behaviour, the threshold limits this performance till a required level of drive is gained. When the drive surpasses the threshold, the motivation becomes positive so that the animal is motivated to perform the related behaviour. Drives for exploring, drinking and lying decrease each time step that the related behaviour is performed and increase when the behaviour is not performed (see Appendix A for values and Boumans et al. [16] for a detailed explanation). The threshold for these behaviours is based on circadian rhythms during the day. The threshold for lying, for example, is based on melatonin levels and lower during night time (0.2) than during day time (0.6). At the same time, the threshold for exploring and drinking is based on a combination of melatonin and cortisol levels and higher during night time than during day time with a value ranging between 0.02 and 0.27 (see Boumans et al. [17] for a detailed explanation).

While motivation for exploring, drinking and lying is simulated using simple variables, i.e. drive and threshold, motivation for feeding is simulated more comprehensively. The drive and threshold variables (Feeding drive and Satiation) to simulate Feeding motivation are based on several metabolic and hormonal processes. When Feeding drive is higher than its Satiation, causing a Feeding motivation above zero, a pig is motivated to feed. Feeding drive is affected by Palatability of the diet, Daily energy balance and the Average circadian rhythm. Satiation is affected by Stomach load and Instant energy balance. When feeding behaviour is performed in the previous minute, Positive feedback (a reinforcement effect) temporarily increases Feeding motivation with a fixed value (0.05). For a more detailed explanation about the underlying processes in the model see [17]. 


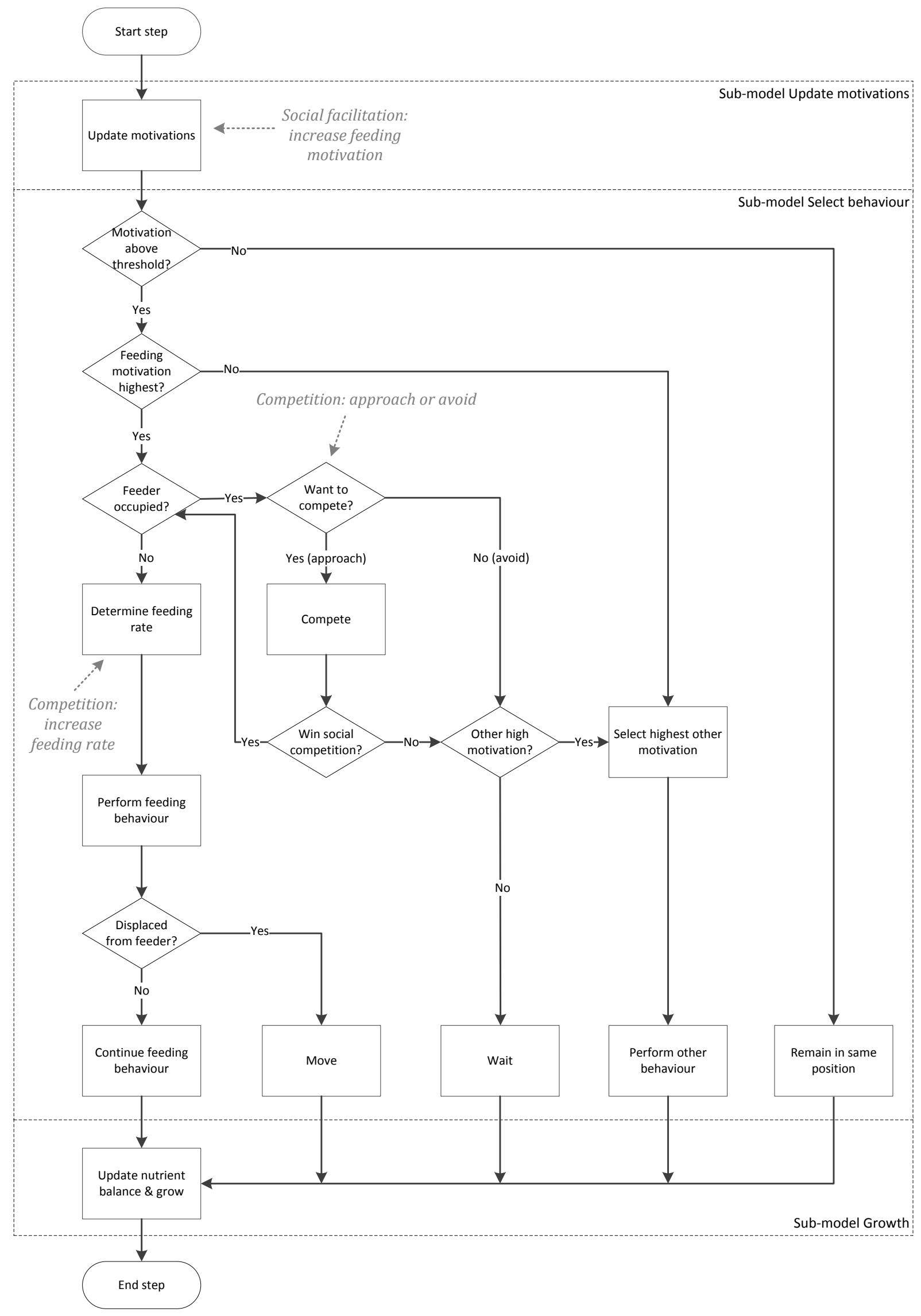

Fig. 4. Flowchart of decisions of an agent each time step. The decision-making process consists of three sub-models 
(surrounded with dotted lines). Social factors are indicated in grey, with text in italics and dotted arrows. All agents (in random order) go through processes in a sub-model, before continuing to the following sub-model.

\subsubsection{Social facilitation}

Social facilitation seems stronger in the appetitive phase than in the consummatory phase [31, 32] and, therefore, is included as a stimulus that temporarily increases feeding motivation of pen mates when a pig is feeding (Social facilitation). Social facilitation is a fixed value of 0.1 that increases feeding motivation of all non-feeding pigs for that time step. The value for this parameter was chosen after calibration of the model to fit empirically observed feeding patterns.

\subsubsection{Select behaviour}

Pigs can initially perform one behaviour per minute: feeding, exploring, drinking, standing or lying. They decide their behaviour based on their motivations for feeding, exploring, drinking or lying. If one or more of these motivations is above zero, the pig wants to perform the behaviour related to the highest motivation. If this behaviour concerns exploring, drinking or lying, the behaviour will be performed. If this behaviour concerns feeding, the pig first checks if the feeder is occupied. If the feeder is occupied, competitive behaviour of avoidance or approach will be performed. If the feeder is free the pig will feed. When none of the motivations is above zero, the pig performs standing (if its last behaviour was active) or lying behaviour (if its last behaviour was lying).

\subsubsection{Competition (feeder is occupied)}

If a pig is motivated to feed, but the feeder is occupied by another pig, the pig decides if it wants to avoid or approach its feeding opponent. This decision is based on behavioural rules adapted from Hemelrijk $[33,34]$ and includes a cost-benefit analysis and estimating the success probability. The social dominance levels of opponents are assumed to be an important factor in this estimation as higher and lower ranked pigs in empirical studies show different feeding strategies. Higher ranked pigs, for example, displaced other pigs from the feeder more often $[35,36]$. In the model, therefore, a pig (i) calculates its Relative dominance, based on its own Dominance (Dominance ${ }_{i}$ ) and the 
Dominance of its opponent ( Dominance $\left._{j}\right)($ equation 1$)$. We assumed an established linear social hierarchy and pigs in the model were randomly assigned a dominance value. The Relative dominance is below 0.5 for lower ranked pigs, and above 0.5 for higher ranked pigs.

(1) $\quad$ Relative dominance $=\frac{\text { Dominance }_{i}}{\text { Dominance }_{i}+\text { Dominance }_{j}}$

It is unlikely that Relative dominance is the only factor that affects the decision of a pig to avoid or approach an opponent. Lower ranked pigs can displace higher ranked pigs as well [36]. We assume that lower ranked pigs will try to avoid direct competition with higher ranked pigs, but might decide to approach them when their feeding motivation is high. A food resource can have an increased value for a hungry individual [see review 4], therefore, we assumed that Feeding motivation increases the value of food and thus the belief that an interaction might be beneficial (Benefit belief) (equation 2). The value of feeding motivation is in this case always above zero and might increase to values up to seven (or higher in extreme cases) when pigs have not fed for a long time. We included an exponential function with the assumption that hungrier animals are more likely to take a risk and reduced the effect with 0.05 . The equation was calibrated to allow Benefit belief to be slightly higher than the Relative dominance (e.g. a pig with a Relative dominance of 0.5 and Feeding motivation of 1 would have a Benefit belief of 0.53, whereas with a Feeding motivation of 6 this would be 0.67$)$.

(2) Benefit belief $=$ Relative dominance $\times \operatorname{Exp}^{(\text {Feeding motivation } \times 0.05)}$

A pig chooses the approach strategy if the value for Benefit belief minus Compete threshold (a fixed value of 0.2 ) is greater than the value randomly drawn (RND) between zero and one (equation 3). The value for Compete threshold was chosen after calibration to fit the number of interactions to empirically observed interactions. This threshold represents a likely factor such as personality or coping style, in which a pig might be more or less reluctant to initiate an interaction. High resistant and more aggressive pigs, for example, are more likely to initiate a fight independent of their likeliness to win $[37,38]$. A pig that chooses the approach strategy will compete with its opponent 
and attempt to displace the opponent pig from the feeder. The alternative is to avoid an opponent and to perform another behaviour (Fig. 4). This behaviour is related to the second highest motivated behaviour or, if no other motivation is above zero, waiting behaviour.

(3) Approach strategy $=$ Benefit belief -Compete threshold $>$ RND $(0,1)$

Wins and losses resulting from an approach strategy are modelled based on the Success probability of both pigs (equation 4). An approach is successful (the opponent is displaced) if the relative Benefit belief of pig $i$ is greater than the value randomly drawn between zero and one. The opponent will be displaced and its location at the feeding place will randomly change to another location in the pen, while the approaching pig starts feeding. An approach is unsuccessful if the value for the Success probability is smaller than the value randomly drawn between zero and one. In this case the opponent pig continues feeding, while the approaching pig performs a behaviour related to its second highest motivation or waits.

(4) Success probability $=\frac{\text { Benefit belief }_{i}}{\text { Benefit belief }_{i}+\text { Benefit belief }_{j}}>\operatorname{RND}(0,1)$

\subsubsection{Feeding}

When a pig that is motivated to feed enters an unoccupied feeder, it first determines its rate of feeding. Feeding rate $(\mathrm{g} / \mathrm{min})$ is based on a physical maximum feeding rate (Feeding rate $\left.{ }_{\max }\right)$, preferred feeding rate (Feeding rate pref $)$, Palatability of the diet with a fixed value of 0.7 , Feeding drive and Group size effect (equation 5, adapted from Boumans et al. [16]). Comparable to the model of Boumans et al. [16], it is assumed that a pig has a Feeding rate ${ }_{\text {pref }}$, based on a physical maximum feeding rate (Feeding rate $e_{\max }$ ) and its Body weight (equation 5a,b). Feeding drive replaces Satiation in the previously used equation in the model of Boumans et al. [16] since this variable better represents a "hungry pig effect" when pigs have not fed for a long time. Furthermore, a Group size effect is included, based on increased Social pressure (with a fixed value of 0.5 ) per additional pig (equation $5 \mathrm{c}$ ). Social pressure is proposed to cause an increase of feeding rate in group housed pigs [26]. Pigs might increase their feeding rate to maximize their feed intake in case they are interrupted at the feeder. It might also reduce the chance of an interaction, since they might use the feeder for a shorter time period. We assumed that Social pressure 
is higher in a larger group size and therefore included a fixed value per additional pig (equation $5 c$ ) to fit the feeding rate within the empirically observed range in various group sizes.

(5) Feeding rate $=$ Maximum $\left(\frac{\text { Feeding rate } \text { pref } \times \text { Palatability diet }}{\exp ^{(-0.15 \times \text { Feding drive })}}+\right.$ Group size effect $)$, Feeding rate $\max$

Wherein:

(5a) Feeding rate $_{\text {pref }}=$ Feeding rate $_{\max } \times{\text { Body } \text { weight }^{-0.25}}^{-25}$

(5b) Feeding rate $\max =\frac{(2.85 \times \text { Bodyweight })}{3.6}$

(5c) Group size effect $=($ group size -1$) \times$ Social pressure

If a pig is displaced from the feeder (during a one-minute time step), then more pigs have fed in the same minute. In this case feeding rate and feeding time of each pig that fed is divided by the number of pigs that fed during that minute to adjust feed intake and feeding time for these pigs in that time step.

\subsubsection{Growth}

At the end of each minute, pigs calculate nutrient and energy use and absorption. Energy remaining after costs for maintenance and activity will be used for body weight increase (for a detailed explanation, see [17]).

\subsection{Model analysis}

\subsubsection{Scenario testing}

The interaction between social factors (competition and social facilitation) and behavioural strategies (avoid and approach) on feeding and social interaction patterns was tested in four scenarios (Table 2). In scenario 1, pigs cannot approach feeding pigs and avoid competition, thus postpone feeding till the feeder is free, whereas in scenario 2, pigs approach and displace feeding pigs each time they are motivated to feed. Scenarios 1 and 2 were created to better understand the specific effect of avoidance and of displacement on feeding patterns and to test whether behavioural strategies chosen in a group explain the change in direction of meal-based feeding patterns from a 
turning point onwards. Scenario 3 tests a likely combination of avoidance and approach to competition, where pigs decide on Benefit belief to approach or avoid feeding pigs and win or lose based on their Success probability. In scenario 4 the effect of social facilitation was added. All scenarios were run for a group size of 1, 2, 5, 10, 15, 20, 25 and 30 pigs (females), while size of the feeding place (only one pig can feed at one time) remained unchanged to represent varying levels of competitive environments. Each combination of scenario and group size was repeated 15 times. This number of simulation runs was sufficient to reach a relatively stable outcome mean and variance. We chose simulation day 30 for analysis, at which the average body weight of pigs was $50 \mathrm{~kg}$. This day was chosen to represent the range of body weight found in empirical studies.

Table 2. Scenarios to test the effect of social factors and behavioural strategies on feeding patterns in pigs.

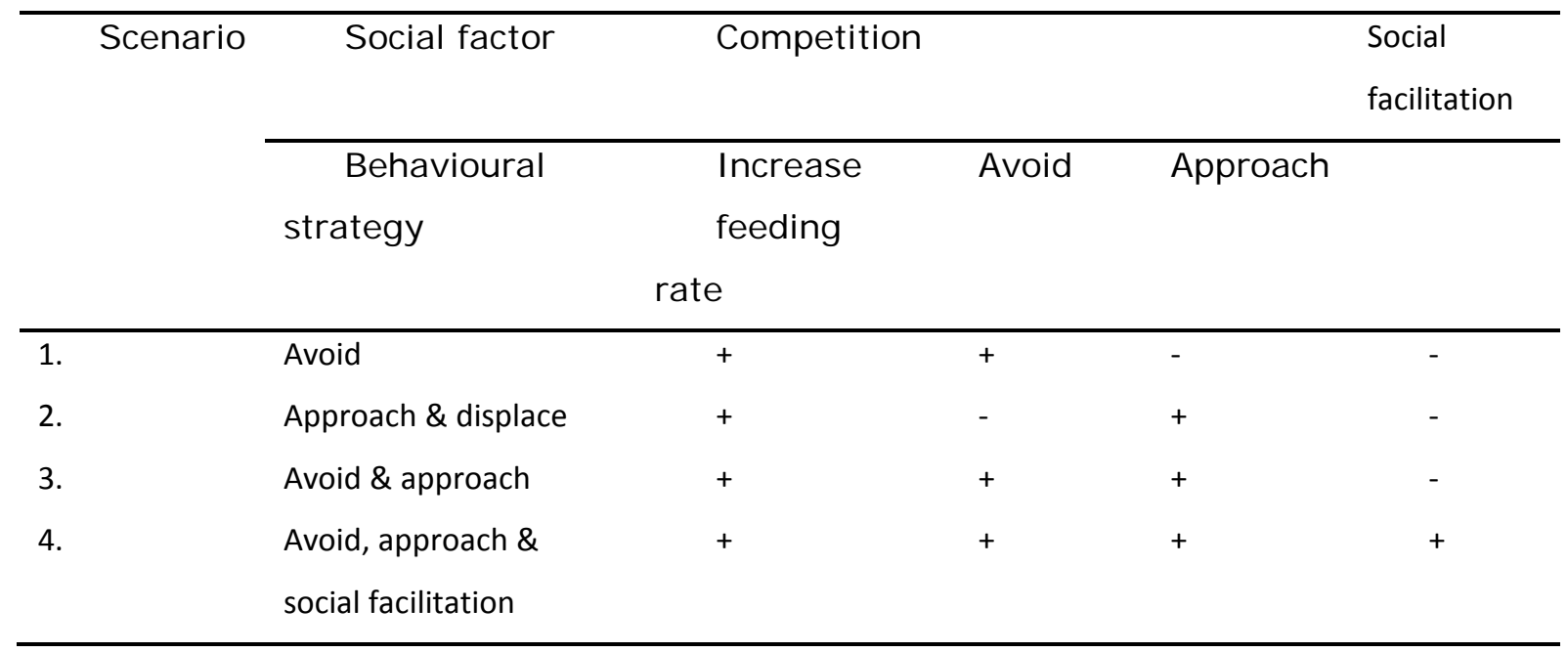

\subsubsection{Sensitivity analysis}

We analysed the sensitivity of feeding and social interaction patterns to parameter settings (Table 3). Parameter values were changed to $20 \%$ above and below the standard value. We tested sensitivity of model results to the effect of various pig characteristics, diet characteristics and (calibrated) behavioural characteristics on feeding and social interaction patterns. The sensitivity analysis was performed in scenario 4 , which also included social facilitation parameters and was thus assumed to be the most realistic scenario. Simulations in the sensitivity analysis were repeated 10 times. This number of runs was sufficient to provide feeding and social interaction patterns with limited variance between simulations. 
Table 3. Input and output variables in the sensitivity analysis (in scenario 4).

\begin{tabular}{|c|c|c|}
\hline Parameter & Standard value & Changed value \\
\hline \multicolumn{3}{|l|}{ Input } \\
\hline Sex & Female & Male, castrated male \\
\hline Feeding rate $_{\max }$ & Equation $5 b$ & Value $\times 0.8$, value $\times 1.2^{1}$ \\
\hline Cortisol amplitude & 0.99 & $0.79,1.19$ \\
\hline \multicolumn{3}{|l|}{ Diet characteristics } \\
\hline Digestible energy diet $(\mathrm{kJ} / \mathrm{g})$ & 14.2 & $11.36,17.04$ \\
\hline Digestion duration (min) & 180 & 144,216 \\
\hline \multicolumn{3}{|l|}{ Behavioural characteristics } \\
\hline Positive feedback & 0.05 & $0.04,0.06$ \\
\hline Social pressure & 0.5 & $0.4,0.6$ \\
\hline Compete threshold & 0.2 & $0.16,0.24$ \\
\hline $\begin{array}{l}\text { Reduced effect feeding } \\
\quad \text { motivation (in equation 2) }\end{array}$ & 0.05 & $0.04,0.06$ \\
\hline Social facilitation & 0.1 & $0.08,0.12$ \\
\hline \multicolumn{3}{|l|}{ Output } \\
\hline \multicolumn{3}{|l|}{ Feeding patterns } \\
\hline \multicolumn{3}{|l|}{ Feed intake (g/day/pig) } \\
\hline \multicolumn{3}{|l|}{ Feeding time (min/day/pig) } \\
\hline \multicolumn{3}{|l|}{ Feeding rate $(\mathrm{g} / \mathrm{min} / \mathrm{pig})$} \\
\hline \multicolumn{3}{|l|}{ Meal frequency (No./day/pig) } \\
\hline \multicolumn{3}{|c|}{ Meal size (g/meal/day/pig) } \\
\hline \multicolumn{3}{|c|}{ Meal duration (min/meal/day/pig) } \\
\hline \multicolumn{3}{|c|}{ Feeder occupation (\%/hour/group) } \\
\hline \multicolumn{3}{|l|}{ Social interaction patterns } \\
\hline \multicolumn{3}{|l|}{ Avoiding (No./day/pig) } \\
\hline \multicolumn{3}{|l|}{ Approaching (No./day/pig) } \\
\hline \multicolumn{3}{|c|}{ Displacing (No./day/pig) } \\
\hline \multicolumn{3}{|c|}{${ }^{1}$ These values represent $20 \%$ variation, an additional sensitivity analysis for this variable was performed with $50 \%$ variation. } \\
\hline \multicolumn{3}{|c|}{ The group size at which feeding patterns reach a turning point in empirical studies may be } \\
\hline \multicolumn{3}{|c|}{ explained by various pig (e.g. breed) and housing conditions (e.g. diet type) that affect competition } \\
\hline \multicolumn{3}{|c|}{ levels. To test this effect in the model, an additional sensitivity analysis was performed with $50 \%$} \\
\hline \multicolumn{3}{|c|}{ variation in Feeding rate $\max$ (for the standard value and this value $\times 0.5$ and $\times 1.5$ ) for every group } \\
\hline \multicolumn{3}{|c|}{ size between 1 and 30 pigs (Feeding rate max $\times 0.5$ was run till group size 20 because in larger group } \\
\hline \multicolumn{3}{|c|}{ sizes pig were not able to reach sufficient feed intake). Maximum feeding rate was chosen as an } \\
\hline \multicolumn{3}{|c|}{ example because the sensitivity analysis showed that of all tested pig and diet parameters, it had the } \\
\hline
\end{tabular}


conflicts (which is the sum of avoiding and approaching) in these simulations, the statistical program $R$ (version 3.2.0) was used [39]. We calculated the sum of squares error per degree of freedom for one linear equation and for two linear equations, in which all possible breaking points were calculated as the intersections between the lines. We selected the group size with best linear fit (regression line) for two linear lines with the smallest value for sum of squares error per degree of freedom as the breaking (turning) point.

The relation between daily feeding time of pigs and turning points in feeding and social interaction patterns at various group sizes was further analysed. Daily feeding time of pigs (in a group size of 2) and the group size at which competition caused a turning point in the feeding and social interaction patterns were plotted (data points were taken from the sensitivity analysis of Feeding rate $_{\text {max }}$ ). Group size 2 was chosen as smallest group size to represent minimal competition without being affected by other factors such as social isolation stress that can occur when pigs are housed individually [32].
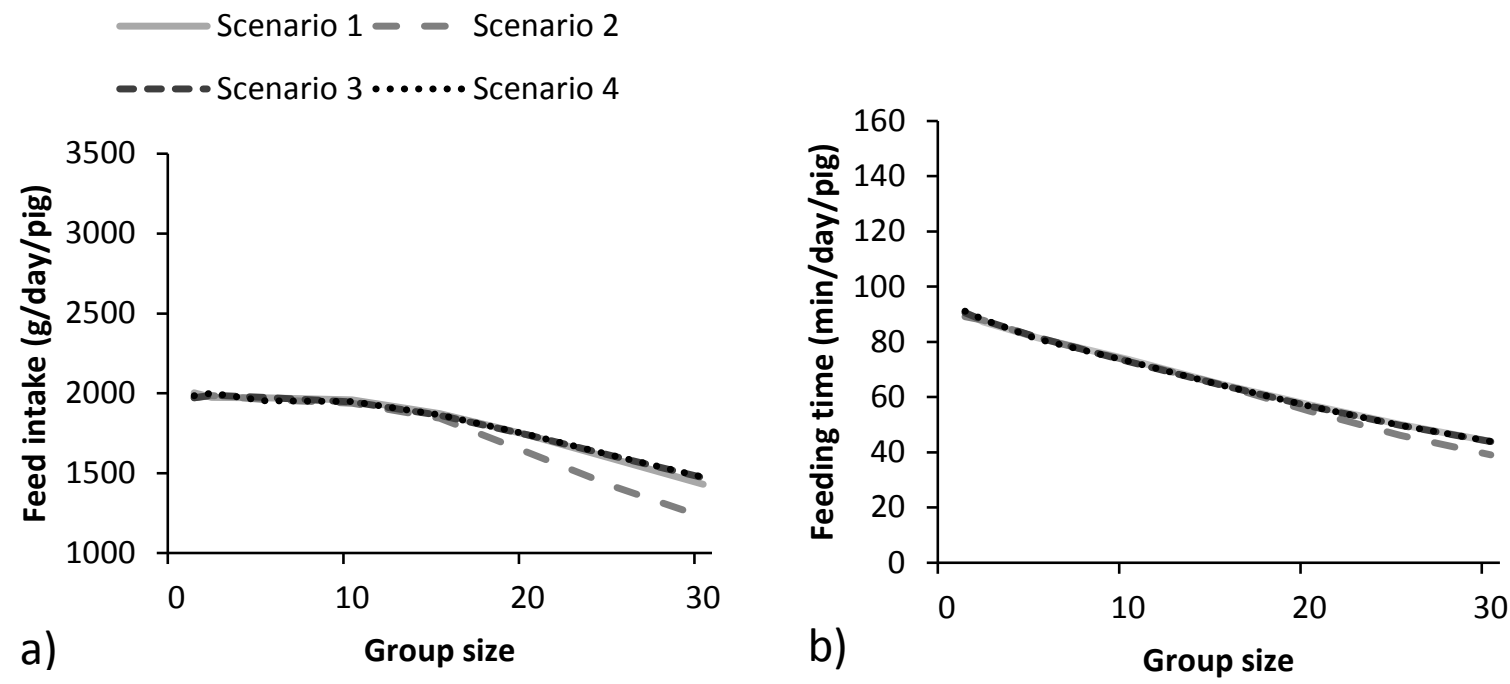

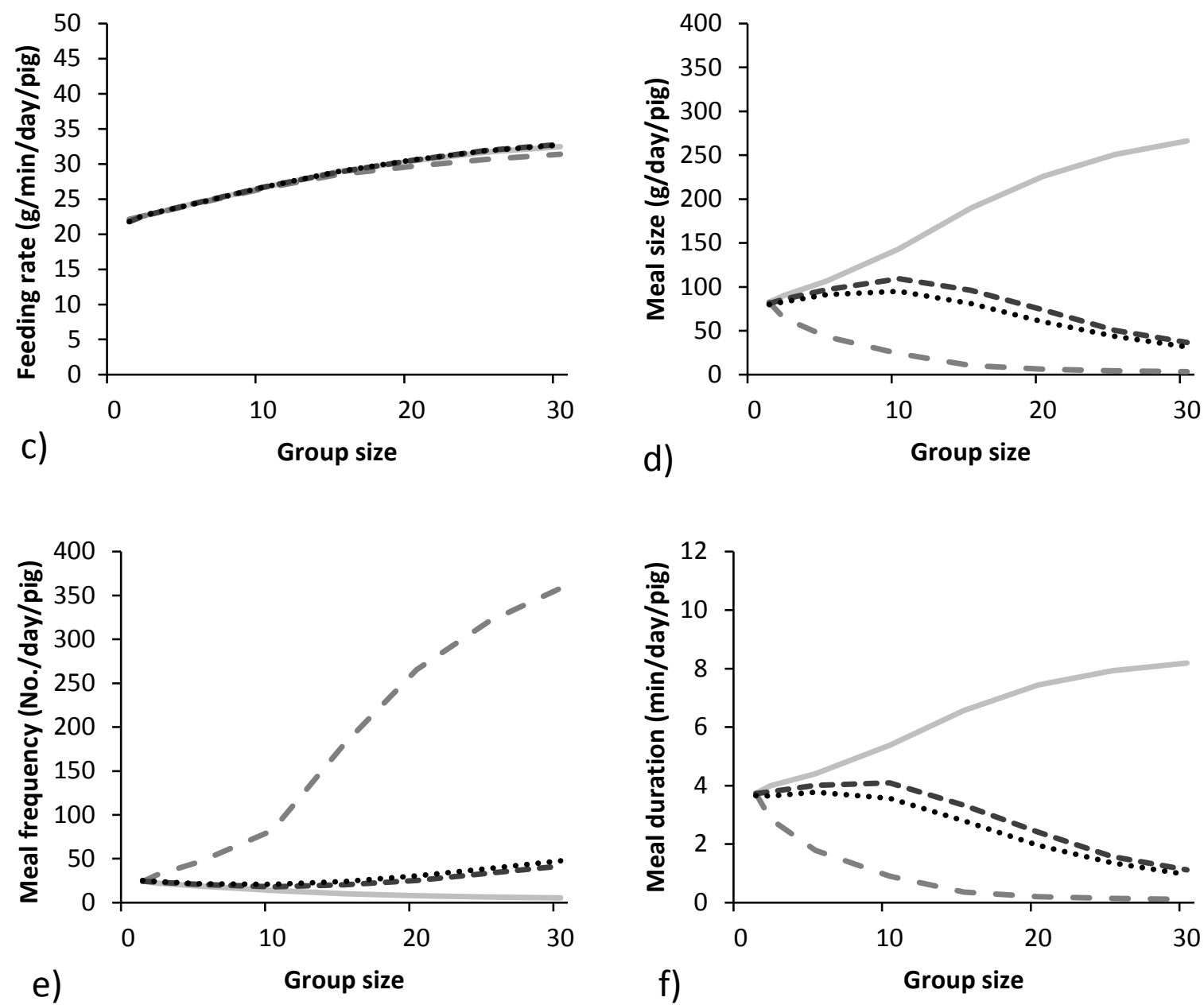

e) Group size

Fig. 5. Average patterns of feed intake (a), feeding time (b), feeding rate (c), meal size (d), meal frequency (e) and meal duration (f) of pigs in various group sizes in four scenarios: 1) avoid, 2) approach and displace, 3) avoid \& approach, and 4) avoid \& approach \& social facilitation. Each simulation result is an average of 15 simulation runs per combination of scenario and group size.

\section{Results}

\subsection{The effect of social factors and behavioural strategies on meal-based patterns}

Fig. 5a-f shows the effect of social factors and behavioural strategies on feeding patterns in four scenarios. Patterns of feed intake, feeding time and feeding rate vary slightly between scenarios (Fig. $5 \mathrm{a}-\mathrm{c}$ ), whereas patterns of meal size, meal frequency and meal duration vary considerably (Fig. $5 \mathrm{~d}$ f). Avoidance behaviour in pigs (scenario 1) increased meal size and duration, whereas meal frequency decreased. Approaching behaviour in pigs (scenario 2) resulted in meal patterns completely opposite to those in scenario 1 . Feeding patterns in scenario 3 and 4 , in which avoidance 
and approaching are combined, are in between patterns observed in scenario 1 and 2, with a clear turning point in pattern development around group size 10. In smaller groups, meal frequency was lower and meal duration and meal size were higher, whereas in larger groups these patterns showed an opposite development. The addition of social facilitation in scenario 4 affected meal patterns only slightly.

\subsection{The effect of social factors and behavioural strategies on hourly feeder occupation}

For group sizes 1, 5 and 10, hourly feeder occupation was similar in all scenarios (Fig. 6a-d). For group size 30 , however, feeder occupation was slightly lower in the early morning in scenarios 1 and 4 . The low feeder occupation at 19:00 $\mathrm{h}$ in all scenarios for group size 1 to 10 was due to a strong increase in melatonin at the beginning of the dark period, which decreased feeding motivation in all pigs simultaneously. In scenario 2, this effect of melatonin was also visible for group size 20 and 30, because feeding motivation on average was low in this scenario as pigs attempted to feed immediately when hungry. It is likely, however, that in reality this effect will be overruled by higher levels of feeding motivation due to more delay in feeding behaviour, as observed in scenarios 1,3 and 4.
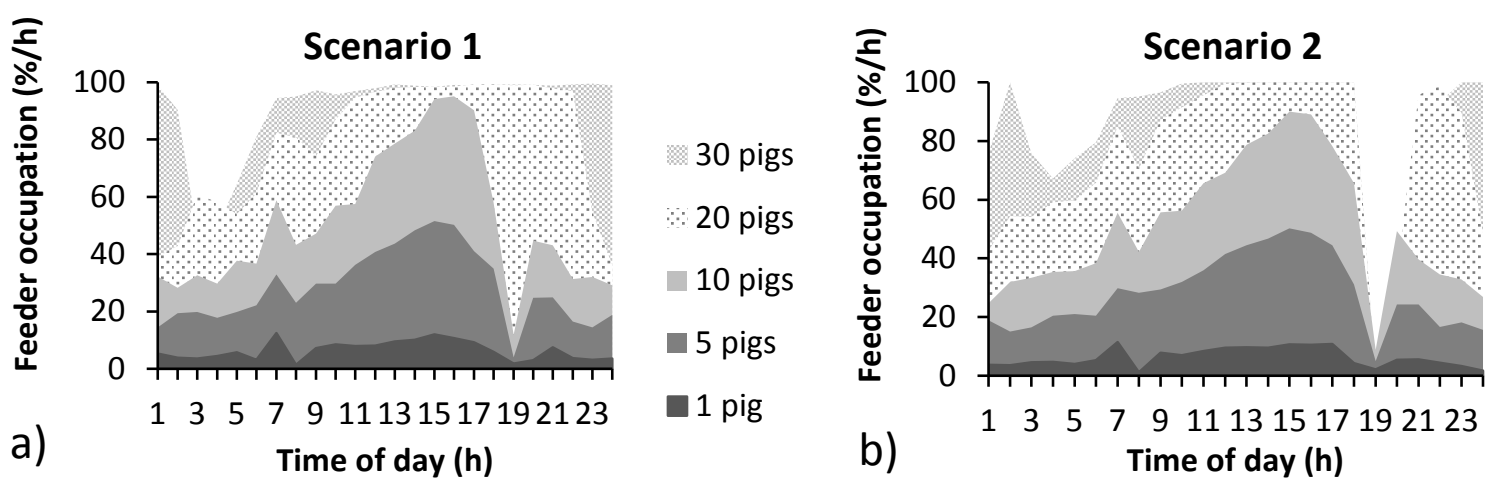

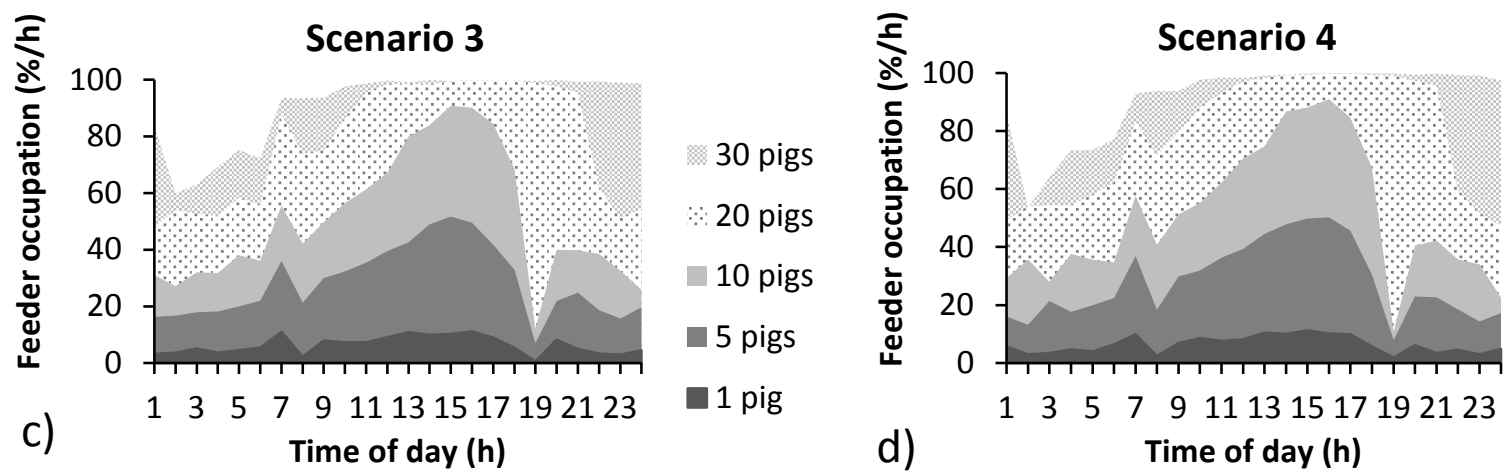

Fig. 6. Average hourly feeder occupation in various group sizes in four scenarios: avoid (a), approach and displace (b), avoid \& approach (c), and avoid \& approach \& social facilitation (d). Each simulation result is an average of 15 simulation runs per combination of scenario and group size.

\subsection{The effect of social mechanisms on social interaction patterns}

Social interaction patterns increased with increasing group size in all scenarios, especially in groups larger than 10 pigs (Fig. 7). In scenario 1, where pigs avoided each other, avoidance increased linearly in group sizes from 10 pigs onwards (Fig. 7a). In scenario 2, where pigs approached and displaced each other, displacement increased quadratically from 10 pigs onwards (Fig. 7b). The patterns in scenario 3 and 4 are relatively similar, but all social interaction patterns are slightly higher in scenario 4 (Fig. 7c-d).
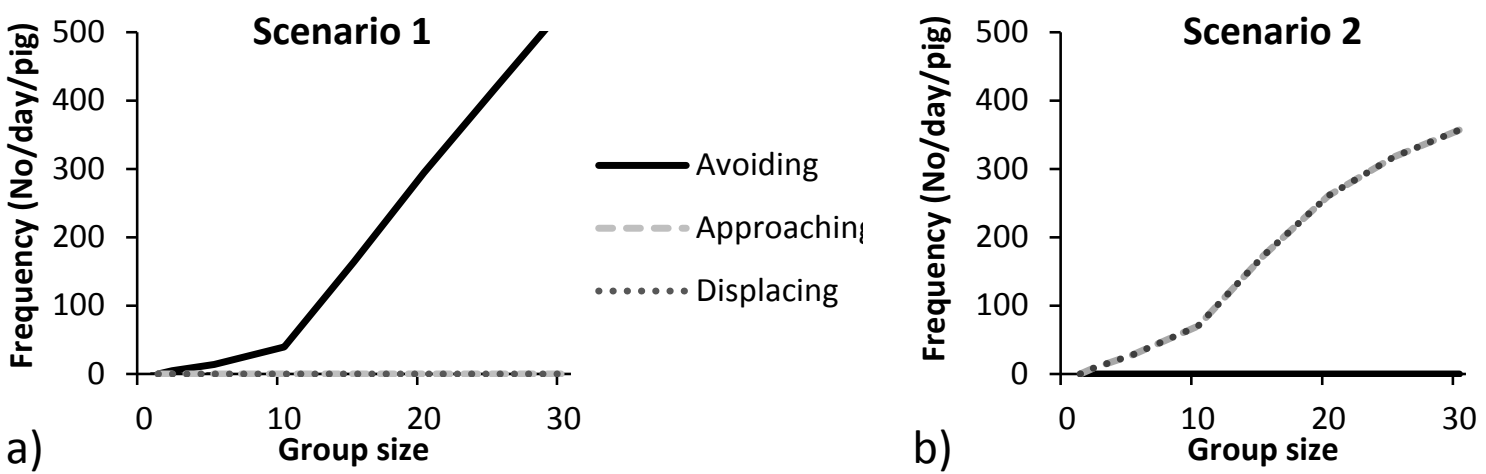

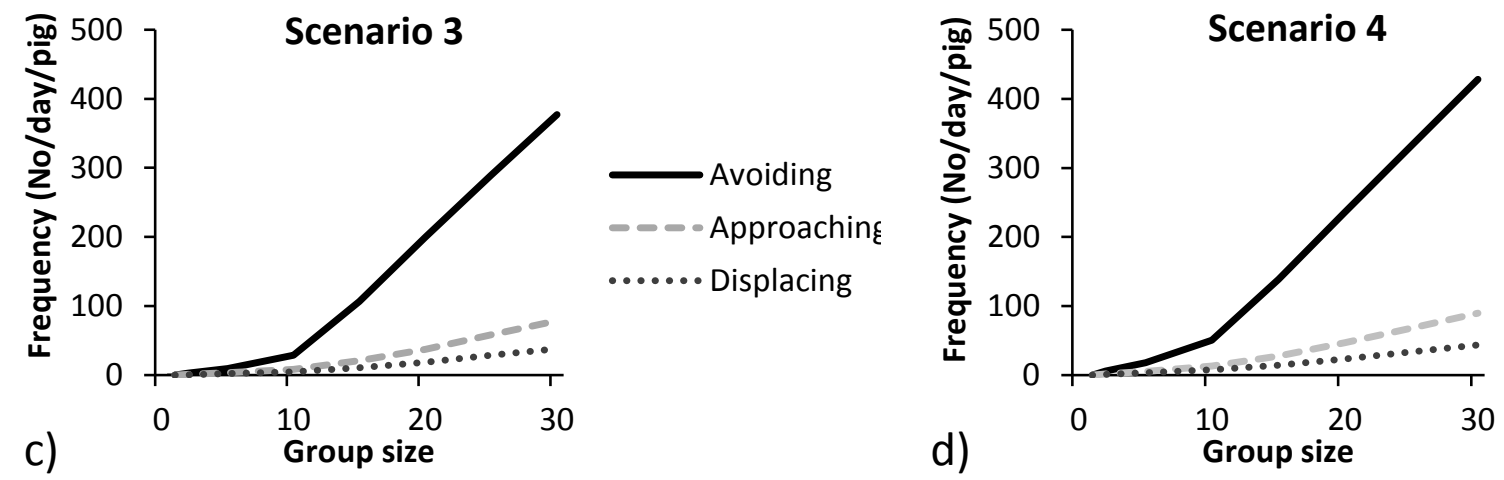

Fig. 7. Average social interaction patterns of pigs in various group sizes in four scenarios: avoid (a), approach and displace (b), avoid \& approach (c), and avoid \& approach \& social facilitation (d). Each simulation result is an average of 15 simulation runs per combination of scenario and group size.

\subsection{Sensitivity analysis}

We analysed sensitivity of the model to parameter settings in scenario 4 , which is the most realistic scenario. The parameters Digestible energy diet and Feeding rate max $_{\text {had }}$ the largest impact on feeding and social interaction patterns. Variation in Digestible energy diet mainly affected daily feed intake and feeding time in the smallest groups, whereas it mainly affected the meal-based patterns and feeding rate and social interaction patterns in the larger groups (see Appendix B, Fig. A1, A2). Comparable to Digestible energy diet, variation in Feeding rate max $_{\text {mainly affected daily feeding }}$ time in the smallest groups and meal frequency in the largest groups, however, feeding rate and meal size was affected similarly in all group sizes and feed intake was affected more in larger group sizes (see Fig. 8 for results with 50\% variation in this parameter). The effect on social interaction patterns was comparable between maximum feeding rate and energy level of the diet. Changing other pig and diet variables (Sex, Cortisol amplitude and Digestion duration) and behavioural parameter values (Positive feedback, Social pressure, Compete threshold, Reduced effect feeding motivation (in equation 2) and Social facilitation) with $20 \%$ had an impact of less than $20 \%$ on the feeding and social interaction patterns (data not shown). 

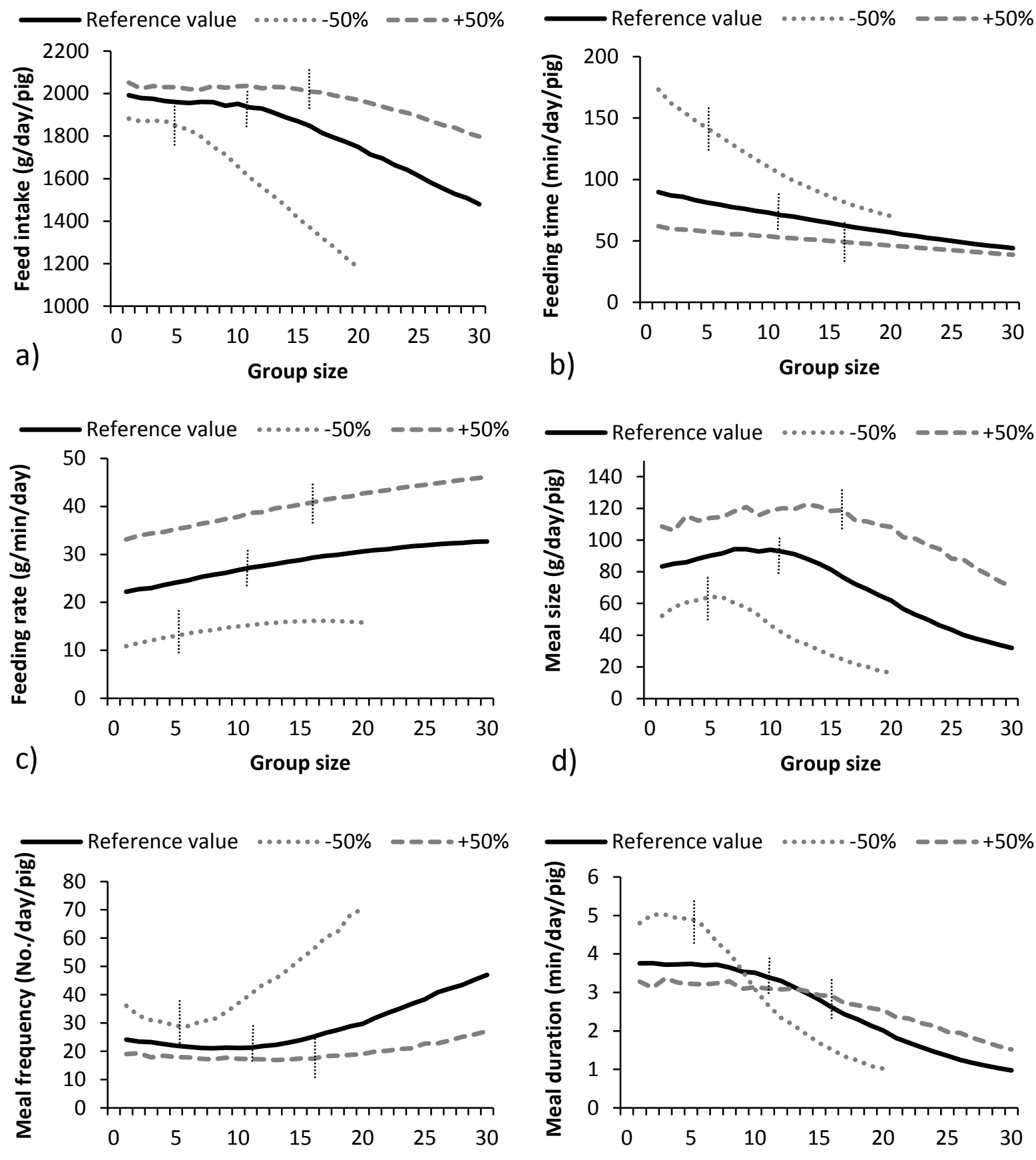

e)

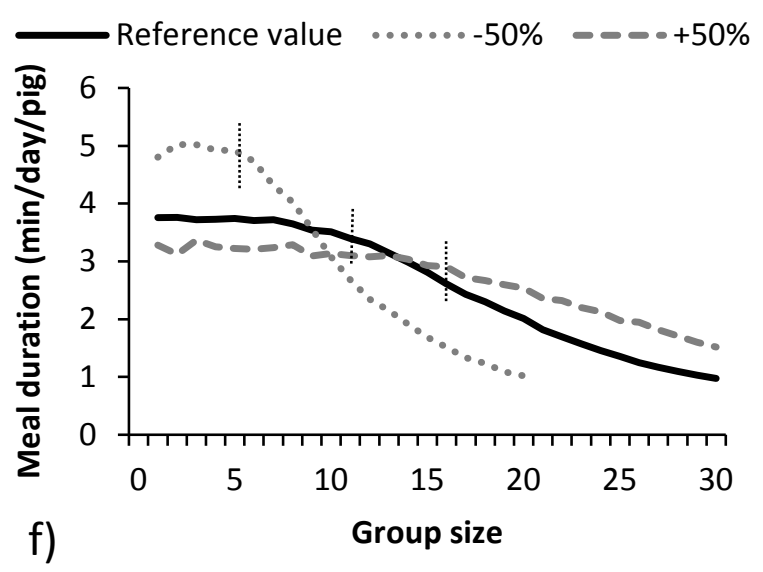

Fig. 8. Sensitivity analysis of patterns of feed intake (a), feeding time (b), feeding rate (c), meal size (d), meal frequency (e)

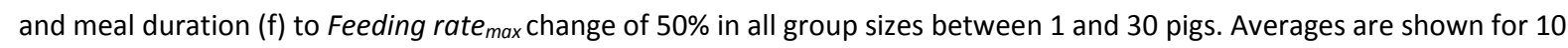
simulation runs per group size in scenario 4 . Vertical dotted lines indicate the group size at which the number of conflicts (= sum of avoiding + approaching) shows a turning point. 


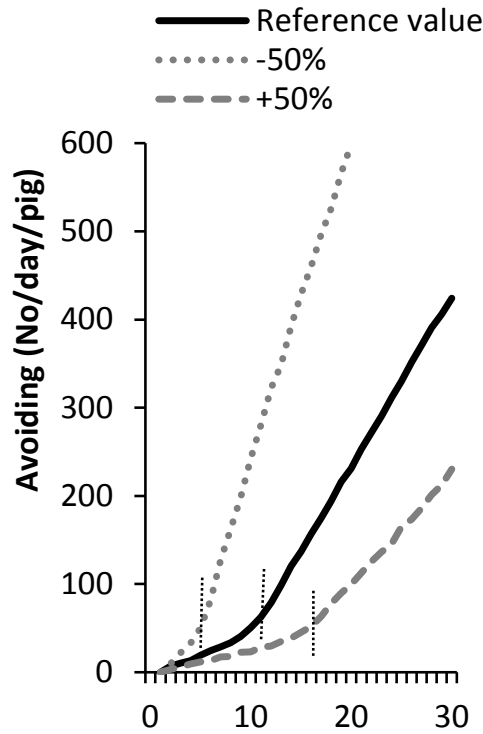

a)

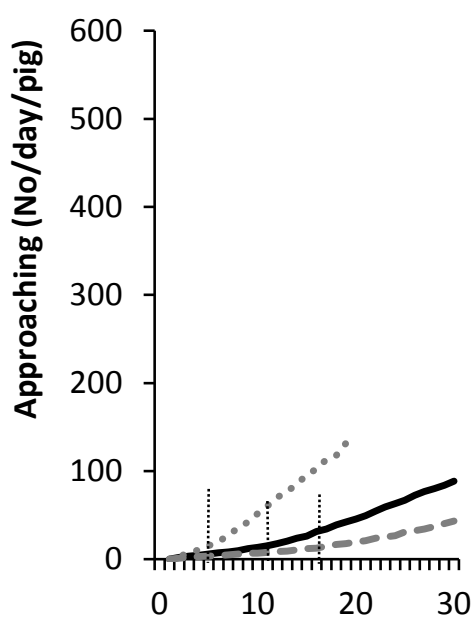

b)

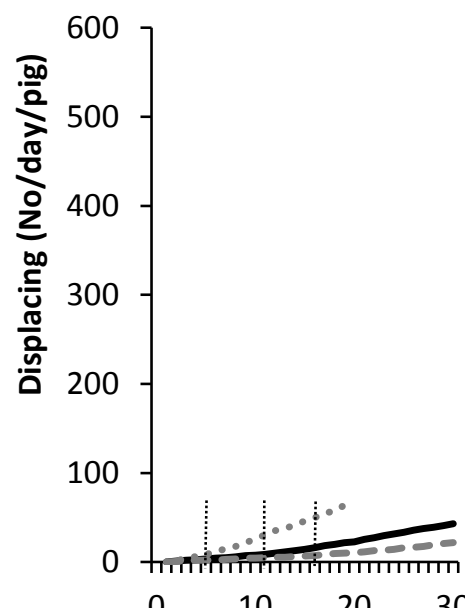

c)

Group size

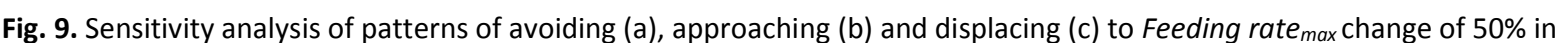
all group sizes between 1 and 30 pigs. Averages are shown for 10 simulation runs per group size in scenario 4 . Vertical dotted lines indicate the group size at which the number of conflicts (=sum of avoiding + approaching) shows a turning point.

\subsection{The effect of maximum feeding rate on a turning point}

A sensitivity analysis on Feeding rate max $_{\text {was }}$ werformed with variation of $50 \%$ for each group size between 1 and 30 pigs. Results show that Feeding rate $_{\max }$ affect group size at which several feeding and social interaction patterns change direction (Fig. 8, 9). The turning points in the average number of conflicts were at group size 5, 11 and 16 for the smallest to largest Feeding rate max $_{\text {, }}$ respectively.

Variation in Feeding rate $_{\max }$ affected the hourly feeder occupation time in the various group sizes. For all sizes, turning points coincided with similar percentages of hourly feeder occupation time. This percentage was about 35\% during night, $60 \%$ during the first feeding peak and $80-100 \%$ the second peak (Fig. 10).

The relation between daily feeding time of pigs and turning points in feeding and social interaction patterns at various group sizes was exponential. Plotting daily feeding time of pigs (in a group size of 2) and the group size at which competition caused a turning point in the feeding and 
social interaction patterns showed an exponential trend (turning point $=30.411 \times \operatorname{Exp}(-0.011 \times$ daily feeding time of pigs (in a group size of 2 )), $R^{2}=0.996$ ).
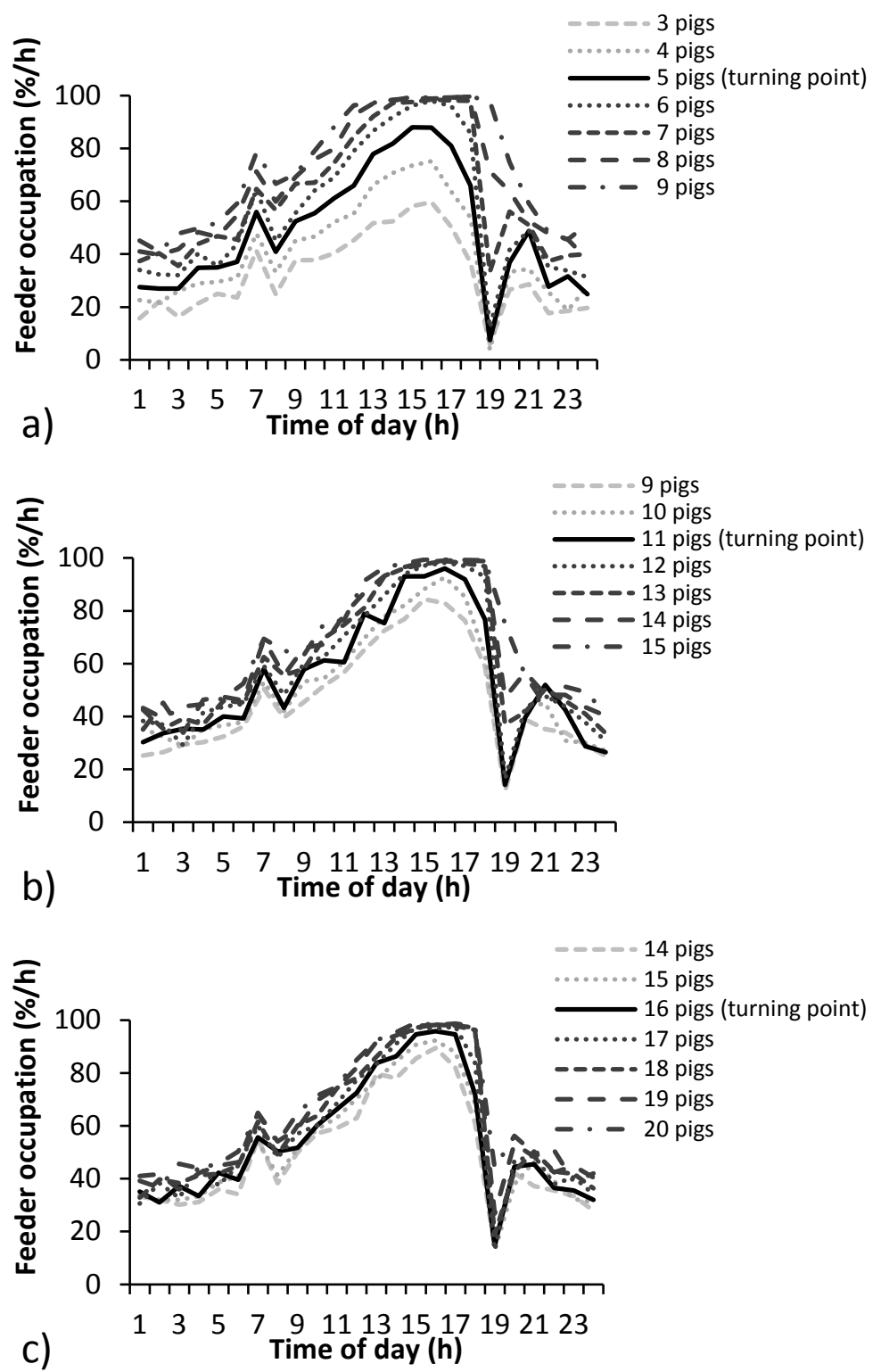

Fig. 10. Sensitivity analysis of hourly percentage of feeder occupation time to Feeding rate max change of $50 \%$ at various group sizes. The graphs represent a change in Feeding rate max $_{\text {of }}-50 \%$ and a turning point at group size 5 (a), a standard Feeding rate $_{\max }$ and a turning point at group size 11 (b) and a change in Feeding rate $\max _{\max }$ of $+50 \%$ and a turning point at group size 16 (c). Data points are from the sensitivity analysis of Feeding rate max $_{\text {with }}$ averages of 10 simulation runs per group size in scenario 4.

\section{Discussion}

We studied the interactions among physiological factors, social factors and behavioural strategies in an $A B M$ to deepen our understanding of mechanisms underlying feeding and social 
interaction patterns in animals, with pigs as a case study. Emergent feeding and social interaction patterns of pigs in the model were compared with empirical patterns. Feeding patterns in pigs varied considerably between empirical studies [e.g. 20-24, 40]. Patterns of feed intake, feeding time and feeding rate varied in absolute level but showed similar trends with increasing group size. Furthermore, the absolute level variation in patterns of daily feeding time between studies decreased with group size. Various factors are known to contribute to variation in feeding patterns in pigs, such as pig and diet characteristics [e.g. 41, 42, 43]. Energy level of the diet and maximum feeding rate represented such factors in the model. The sensitivity analysis showed that these factors affected physiological processes and explained the absolute level variation in patterns of daily feed intake, daily feeding time and feeding rate between studies, especially in smaller groups.

In contrast to the above mentioned feeding patterns, meal-based patterns (meal frequency, meal duration and meal size) varied not only in absolute level, but also in trends between empirical studies, especially in larger groups. Although initially there seemed no logical explanation for this variation, model results show that behavioural strategies of pigs can explain these results. Pigs in larger groups experienced more competition and conflicts around the feeder, in which they had to decide to avoid or approach these conflicts. An increase in meal size and duration, and decrease in meal frequency was explained in the model by pigs that chose to avoid conflicts, as shown in scenario 1 . Simulations in which pigs chose to approach and displace other pigs, however, resulted in opposite meal-based patterns, as shown in scenario 2. This suggests that decreasing meal size and duration and increasing meal frequency patterns indicate a competitive environment with high displacement levels, whereas opposite patterns indicate a low competitive environment with low displacement levels. This result is in line with the concepts of procurement and consumption costs. Procurement costs make it difficult to gain access to food (as in scenario 1), whereas consumption costs represent the costs of retaining access to food (e.g. due to competition as in scenario 2). Procurement costs reduce meal frequency and increase meal size, whereas consumption costs cause the opposite [e.g. 44]. These trends are comparable to our model results. 
Model results thus indicate that pig and diet characteristics mainly explain patterns of feed intake, feeding time and feeding rate, while behavioural strategies of individuals explain variation in patterns of meal frequency, meal duration and meal size. The effect of behavioural strategies was especially evident in larger groups from a certain group size (turning point) onwards, where mealbased and social interaction patterns changed direction. These turning points were also observed in empirical studies, although the group size related to this point seems to vary between studies. Hyun and Ellis [21], Hyun and Ellis [22], for example, showed an early turning point around groups of 4 to 8 pigs, whereas Nielsen et al. [23] found a turning point around 10 to 15 pigs. Our model results explain this turning point by variation in daily feeding time between pigs, which affects feeder occupation time and therefore competition levels in groups. The sensitivity analysis showed that a decreased maximum feeding rate in pigs moved the turning point to a lower group size, whereas an increased maximum feeding rate elevated it. In this analysis, higher group size turning points were associated with low levels of daily feeding time and lower group size turning points were associated with high levels of daily feeding time. This is in agreement with empirical studies, where pigs with a lower daily feeding time (i.e. 68 minutes per pig per day) showed a turning point in meal-based patterns at a larger group size (i.e. around 10 to 15 pigs) in Nielsen et al. [23], while pigs with a higher daily feeding time (i.e. 130 minutes per pig per day) showed a turning point at a smaller group size (i.e. around 4 to 8 pigs) in Hyun and Ellis [21]. Feeder occupation, therefore, was also higher in Hyun and Ellis (2001) than in Nielsen et al. (1995). This might explain why daily feed intake decreased and the number of displacements increased in the largest groups in the study of Hyun and Ellis [21], even though group sizes in that study $(2,4,8$ and 12$)$ were on average small and would not suggest high competition levels.

Following the reasoning above, this suggests that reducing feeding time is a potential first adaptation to reduce competition for a food resource in group housing. A pig can reduce its feeding time by reducing its daily feed intake or increasing its feeding rate. It is assumed that pigs desire to obtain a certain level of daily feed intake, therefore, an increase of feeding rate is a likely adaptation to 
competition [26]. The ability to increase feeding rate, however, can be different among pigs because of physical limitations, such as feed intake capacity of the mouth [45]. In addition, this ability increases to a certain extent with increasing body weight [16]. Pigs that are physically limited, therefore, have a higher risk of not reaching the desired daily feed intake. This is shown in the studies of Hyun and Ellis [21], Hyun and Ellis [22], where a smaller response in feeding rate was the main difference between growing and finishing pigs, and the smaller growing pigs were not able to maintain daily feed intake levels, whereas the larger finishing pigs were [22]. Furthermore, the feeding patterns in the sensitivity analysis with a $50 \%$ decrease of maximum feeding rate are in agreement with the patterns in the study of Hyun and Ellis [21], which confirms that a factor such as limited feeding rate can explain the feeding patterns in that study.

The sensitivity analysis with variation in maximum feeding rate for each group size showed that with default model parameters, the turning point emerged at group size 11 in scenario 4 . With a $50 \%$ lower feeding rate, however, the turning point emerged at group size 5 , whereas with a $50 \%$ higher feeding rate it emerged at group size 16. These turning points showed an exponential relation with feeding time of pigs, suggesting that feeding time of a pig housed in a small group can predict at which group size competition levels for a food resource would increase, and, hence, a turning point in feeding and interaction patters would emerge. Based on the observed average daily feeding time of 130 minutes in Hyun and Ellis [21] and 118 minutes per pig in Hyun and Ellis [22] in group size 2, the turning points for these studies were calculated at 7.3 and 8.3 pigs respectively. These turning points fit in the observed feeding patterns of these studies. Furthermore, the turning point of 7.3 is in agreement with the amount of displacements in the study of Hyun and Ellis [21], which were significantly higher for group size 8 and 12 . The turning point (based on an average feeding time of 68 minutes in the smallest group size of 5 pigs) for the study of Nielsen et al. [23], was calculated at a group size of 14.4 pigs. This value is comparable with the empirical data, where patterns of meal frequency, meal duration and meal size were significantly different between group size 5 to 15 and group size 20. That increased competition above group size 15 did not affect displacement behaviour 
in that study, can be explained by a high level of avoidance as behavioural strategy. This was also confirmed by the feeding patterns in that study, which were similar to the feeding patterns in scenario 1, were pigs did not compete. The high level of avoidance behaviour can be related to pig characteristics, such as coping style and aggression level, or group dynamics, such as a clear and stable social hierarchy.

Besides daily feeding time, also the hourly feeder occupation distribution seems to be related to turning points. Hourly feeder occupation in group size 8 reached about 50\% during the night and $80 \%$ during the day in the study of Hyun and Ellis [21], and about 50\% during the night and $90 \%$ during the day in group size 20 in the study of Nielsen et al. [23]. In both studies, a proportionally larger increase in nightly than in daily feeder occupation was observed in these group sizes compared to smaller group sizes in these studies. This proportionally larger nightly increase in feeder occupation might occur after exceeding a turning point in group size. The simulation results were in line with these empirical results, and suggest a relation between a turning point and an hourly feeder occupation time above $35 \%$ during the night, and above $80 \%$ during the highest day peak.

We expected that social facilitation would stimulate behavioural synchrony in feeding behaviour and explain the more clustered distribution of feed intake during day time in group housed pigs compared to the more equal distribution in individually housed pigs. This more clustered distribution, however, also occurred in scenarios without the mechanism of social facilitation. Furthermore, the addition of social facilitation in scenario 4 showed no further clumping effect. This suggests that a clustered distribution of feed intake is more likely caused by physiological factors, such as daily energy balance and hormonal circadian rhythms, than by social factors, such as social facilitation and behavioural synchrony. Social facilitation only slightly decreased meal duration and meal size, and increased meal frequency and interactions in scenario 4 . This suggests that social facilitation slightly increases competition, but plays a minor role in feeding patterns in group-housed pigs with one feeding place. This is comparable to the findings in laying hens of Collins et al. [46], 
who concluded that social facilitation affects behavioural synchronicity and clustering around a feeder, but that this behaviour is mainly resource driven rather than socially driven. For grouphoused pigs, the minor effect of social facilitation might also be due to experience, in which pigs have learned that only one pig can feed at the time and there is no use in responding to a social facilitation stimulus.

In this paper we presented a mechanistic $A B M$, in which feeding and social interaction patterns emerge from a complex interaction between physiological, behavioural and environmental factors. The model was built stepwise, whereby first internal processes, such as metabolic and endocrine processes affecting growth and feeding motivation, were modelled and validated $[16,17]$. The model was not tested independently with an empirical dataset, but was tested with POM. POM was used to systematically build and analyse the model $[18,19]$. Identified patterns from literature were used to decide on what factors and mechanisms to include, and to calibrate and to validate the model. In the current study, social factors and group dynamics were added to the model, allowing to gain more insight in the complexity of internal and external factors underlying pig behaviour. The integration of factors from various disciplines (e.g. nutrition, energetics, endocrinology and ethology) and the level of detail allows to compare the model with a wide range of empirical patterns for validation. Although validation with POM does not provide equally strong evidence as validation with an independent dataset, the large number of patterns that are comparable between the model and empirical data, and the validation of the model in several phases, gives confidence that the model contains the appropriate mechanisms and provides realistic explanations for feeding and social interaction patterns in pigs.

Our study shows how physiological factors can affect interactions and behavioural patterns (e.g. affect competition levels at certain times and affect behaviour such as feeding rate) and increases our understanding of behaviour. The relation between a physiological state of an animal and its behaviour, as included in our model, is studied relatively little, although physiological influence on 
animal behaviour is becoming increasingly evident nowadays [47]. This model can be used as a tool in further research to study the effect of social factors and group dynamics on individual variation in feeding and social interaction patterns. Our model allows, for example, to study contradictory and illunderstood empirical patterns in meal frequency and meal duration of dominant and subordinate animals, such as observed in pigs [e.g. 36]. In our step-by-step approach, we can gradually test potential explanatory factors, such as group composition, individual coping styles and hierarchical stabilities, and disentangle their effect on behaviour.

The use of agent-based modelling in understanding animal behaviour in combination with a relatively detailed level of physiological factors is novel in research. We believe that this approach can be valuable in further studies in animal behaviour. Although the model was developed for pigs, the included factors are likely important in the behaviour of many animal species. Model values can be adjusted and mechanisms can be changed to fit characteristics, for instance, for other farm animals in a similar environment or wild animal species in environments were food resources are scarce or easily defendable.

To conclude, our study increased understanding of feeding and social interaction patterns in animals and underlying mechanisms. The ABM results suggest that the social factor 'competition' largely determines at what group size a turning point in feeding and social interaction patterns emerges. Below a turning point, competition between pigs is affected by pig and diet characteristics. These pig and diet characteristics affect patterns of daily feeding time, daily feed intake and feeding rate, and explain the majority of the variation in these patterns between empirical studies. Daily feeding time of pigs appeared a good indicator to predict the group size at which a turning point in feeding and social interaction patterns emerges. A feeder occupation above $35 \% / \mathrm{h}$ during the night and $80 \% / \mathrm{h}$ during the day can also indicate a turning point in patterns. Beyond that turning point, conflicts between pigs occur more commonly and behavioural strategies to adapt to these conflicts mainly explain variation between empirical studies in meal-based and social interaction patterns. 
Social facilitation can increase competition, but appeared unimportant in the causation of feeding and social interaction patterns of pigs in the model. The modelling approach used in this study can be valuable fort gaining more understanding of mechanisms underlying patterns of animal behaviour.

\section{Acknowledgements}

We would like to thank Aart van der Linden and Cindy Klootwijk for advice in model analysis and

Lia Hemerik for advice and writing code in $\mathrm{R}$ to calculate breaking points in our model data. This

research was funded by the IP/OP program 'Complex Adaptive Systems' of Wageningen UR.

\section{Appendix A. Overview of state variables in the model}

Table A1. Global and agents-own state variables, default values or ranges with units of measurement and appearance in model versions. ${ }^{1}$

\begin{tabular}{|c|c|c|c|c|}
\hline Variable & Description & $\begin{array}{l}\text { Default/ range } \\
\text { values }^{2}\end{array}$ & Unit & $\begin{array}{l}\text { Model } \\
\text { version }^{3}\end{array}$ \\
\hline \multicolumn{5}{|c|}{ Globals (variables applied to whole simulation environment, including all agents) } \\
\hline \multicolumn{5}{|l|}{ Time } \\
\hline Days & Number of days since start simulation & $1-120$ & Days & $1,2,3$ \\
\hline Minutes & Time of the day in minutes (within 24 hour) & $0-1439$ & Minutes & $1,2,3$ \\
\hline \multicolumn{5}{|l|}{ Housing } \\
\hline Housing-size-width & Number of grid cells indicating the size of the pen (width) & 10 & Number & $1,2,3$ \\
\hline Housing-size-height & Number of grid cells indicating the size of the pen (height) & 6 & Number & $1,2,3$ \\
\hline $\mathrm{Nr}$-of-feeders & Number of feeding spaces (location to feed) & 1 & Number & $1,2,3$ \\
\hline Feeders & Location(s) to feed & Patch 0,3 & Grid cell & $1,2,3$ \\
\hline Drinker & Location to drink & Patch 9,5 & Grid cell & $1,2,3$ \\
\hline Start-light-period & Start of the light period during a day & 6 & Hour & $1,2,3$ \\
\hline Start-dark-period & Start of the dark period during a day & 18 & Hour & $1,2,3$ \\
\hline Temperature & Ambient temperature in the pen & 22 & Celsius & $1,2,3$ \\
\hline \multicolumn{5}{|l|}{ Pigs } \\
\hline $\mathrm{Nr}$-of-gilts & Number of gilts (female pigs) in the pen & $0-30$ & Number & $1,2,3$ \\
\hline Nr-of-males & Number of male pigs in the pen & $0-30$ & Number & $1,2,3$ \\
\hline Nr-of-barrows & Number of barrows (castrated male pigs) in the pen & $0-30$ & Number & $1,2,3$ \\
\hline Initial-weight & Initial body weight of pigs at the start of a simulation & 27 & $\mathrm{Kg}$ & $1,2,3$ \\
\hline PO & Initial protein weight of a pig at the start of a simulation & 4 & $\mathrm{Kg}$ & $1,2,3$ \\
\hline MinLP-ratio & $\begin{array}{l}\text { Minimum ratio of lipid and protein in the body (separately listed in } \\
\text { the model for gilts, males and barrows) }\end{array}$ & 1 & Unitless (0-1) & $1,2,3$ \\
\hline Mean-Pd-gilts & $\begin{array}{l}\text { Mean deposition of body protein that affects growth potential of } \\
\text { gilts }\end{array}$ & 137 & g/day & $1,2,3$ \\
\hline Mean-Pd-males & $\begin{array}{l}\text { Mean deposition of body protein that affects growth potential of } \\
\text { males }\end{array}$ & 151 & g/day & $1,2,3$ \\
\hline Mean-Pd-barrows & $\begin{array}{l}\text { Mean deposition of body protein that affects growth potential of } \\
\text { barrows }\end{array}$ & 133 & g/day & $1,2,3$ \\
\hline DR-MEL-night & Melatonin level during darkness & 0.80 & Unitless (0-1) & $1,2,3$ \\
\hline DR-MEL-day & Melatonin level during daylight & 0.40 & Unitless (0-1) & $1,2,3$ \\
\hline Cortisol-amplitude & Variation in cortisol levels during the day & 0.99 & Unitless (0-1) & 2,3 \\
\hline $\begin{array}{l}\text { Fixed-positive- } \\
\text { feedback }\end{array}$ & $\begin{array}{l}\text { Reinforcement effect to stimulate continuation when feeding is } \\
\text { performed }\end{array}$ & 0.05 & Unitless (0-1) & $1,2,3$ \\
\hline Digest-duration & Total time to digest feed in the gut (passage time in small intestines) & 180 & Minutes & $1,2,3$ \\
\hline Compete-threshold & Threshold to compete for access to the feeder & 0.2 & Unitless (0-1) & 3 \\
\hline FM-effect-interaction & Effect of feeding motivation to compete for access to the feeder & 0.05 & Unitless (0-1) & 3 \\
\hline FR-pig-effect & Represents an increase in FR of $0.5 \mathrm{~g} /$ per pig & 0.5 & g & 3 \\
\hline
\end{tabular}


Social-facilitation-

increase

A stimulus that temporarily increases feeding motivation of all not feeding pigs that time step

Increase-lying-energy Motivational energy increase per time step affecting lying behaviour Increase-exploring Motivational energy increase per time step affecting exploring behaviour

energy

Increase-drinking-

Motivational energy increase per time step affecting drinking behaviour

energy

Cost-energy-lying

Motivational energy decrease when lying behaviour performed

Motivational energy decrease when exploring behaviour performed

Cost-energy-

exploration

Cost-energy-drinking Motivational energy decrease when drinking behaviour performed

Feed (at the feeding location)

DE-content-diet Digestible energy level of the diet

Palatability Palatability of the diet

Dietary-AA-content Content of amino acids in the diet (separately listed in the model for Lysine, Methionine, Methionine+ Cystine, Threonine, Tryptophan and Isoleucine)

Dietary-total-protein- Amount of total protein in the diet

content

Apparent-AA-

availabilities

Apparent amino acid availabilities in the diet (separately listed in the model for Lysine, Methionine, Methionine+ Cystine, Threonine, Tryptophan and Isoleucine)

Apparent-protein- Apparent protein availability in the diet

availabilities

Balanced-protein-

Apparent amino acid utilisation for maintenance (separately listed in

AA\%bp

the model for Lysine, Methionine, Methionine+ Cystine, Threonine,

Tryptophan and Isoleucine)

Gross-energy-content Gross energy content of protein in the feed

protein

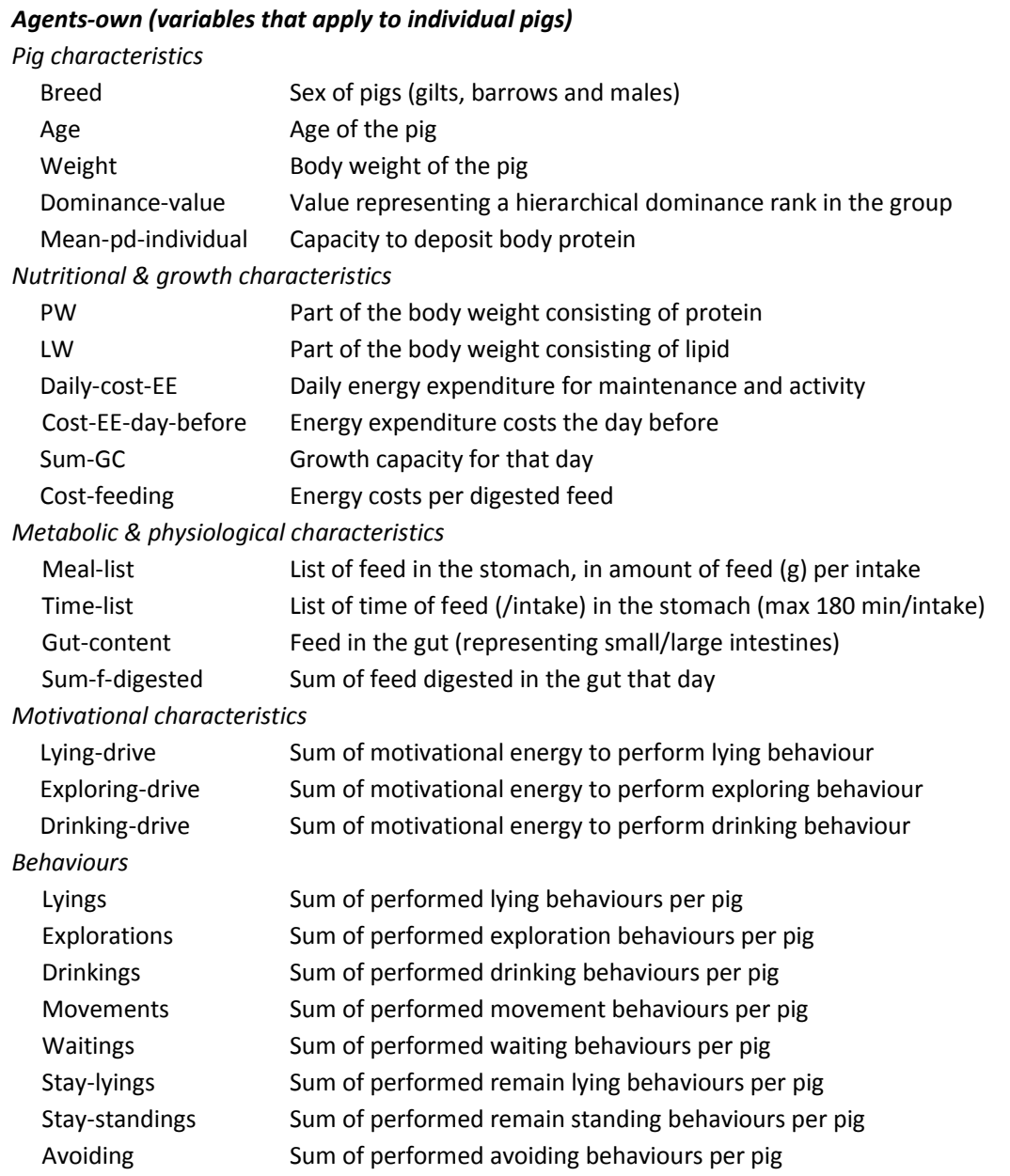

Unitless (0-1)

$1,2,3$

0.033

Unitless (0-1) 1, 2, 3

0.001

Unitless (0-1)

$1,2,3$

0.054

Unitless (0-1) 1, 2, 3

Unitless (0-1) 1, 2, 3

Unitless (0-1) 1, 2, 3

$\mathrm{kJ} / \mathrm{g}$

$1,2,3$

14.2

0.7

Unitless (0-1)

$1,2,3$

$\mathrm{g} / \mathrm{kg}$

$1,2,3$

$\mathrm{g} / \mathrm{kg}$

$1,2,3$

Unitless (0-1)

Unitless (0-1)

$\begin{array}{lll}4-20 & \mathrm{Kg} & 1,2,3 \\ 4-50 & \mathrm{Kg} & 1,2,3 \\ -7000-9000 & \mathrm{~kJ} & 1,2,3 \\ -2500-9000 & \mathrm{~kJ} & 1,2,3 \\ 12000-35000 & \mathrm{~kJ} & 1,2,3 \\ 0.09 & \mathrm{~kJ} / \mathrm{g} & 2,3 \\ & & \\ - & \text { Number } & 2,3 \\ - & \text { Number } & 2,3 \\ 0-1 & \text { Kg } & 1,2,3 \\ 0-3500 & \mathrm{~g} & 1,2,3 \\ & & \\ 0-0.7 & \text { Unitless } & 1,2,3 \\ -0.3-0.3 & \text { Unitless } & 1,2,3 \\ -0.3-0.3 & \text { Unitless } & 1,2,3 \\ & & \\ & \text { Number } & 1,2,3 \\ & \text { Number } & 1,2,3 \\ & \text { Number } & 1,2,3 \\ & \text { Number } & 1,2,3 \\ & \text { Number } & 3 \\ & \text { Number } & 3 \\ & \text { Number } & 3 \\ & \text { Number } & 3 \\ & & \end{array}$


Being-avoided Active-interaction

Succeed-displacing

Fail-displacing

Displaced

Resisted-displacing

Day-feed-intake

Feeding-minutes

Duration-bout

\section{Feeding-bouts}

Feed-intake-meal

Minutes-since-last-

feeding

Total-meal-intervaltime
Sum of being avoided per pig

Sum of interactions per pig

Sum of successful displacing attempts per pig

Sum of failed displacing attempts per pig

Sum of displacements per pig

Sum of resisted displacements per pig

Sum of feed intake of a pig during the day

Sum of feeding time of a pig during the day

Meal duration

Sum of meals of a pig during the day

Amount of feed intake per meal

Time since last meal (interval time between meals)
Number

Number

Number

Number

Number

Number

g/day

Minutes/day

Minutes/mea

I

Number/day

g/meal

Minutes

1-80

20-600

$1-400$

1-1390

Minutes
$1,2,3$

$1,2,3$

$1,2,3$

$1,2,3$

$1,2,3$

,, 3

$1,2,3$

1 For a detailed explanation of this Table see the ODD related to the model on the website of CoMSES

(https://www.comses.net/codebases/5628/releases/1.1.0/)[48]. ${ }^{2}$ Default or range value in model version $3 .{ }^{3}$ The model described in this study builds on previous models. This column indicates in which version variables were included: $1=1^{\text {st }}$ model published [16], $2=2^{\text {nd }}$ model published [17], $3=3^{\text {rd }}$ model described in the current study and model and ODD published on the CoMSES website [30, 48].

\section{Appendix B. Sensitivity analysis of patterns to diet energy parameter change of}

\section{$20 \%$ in various group sizes}

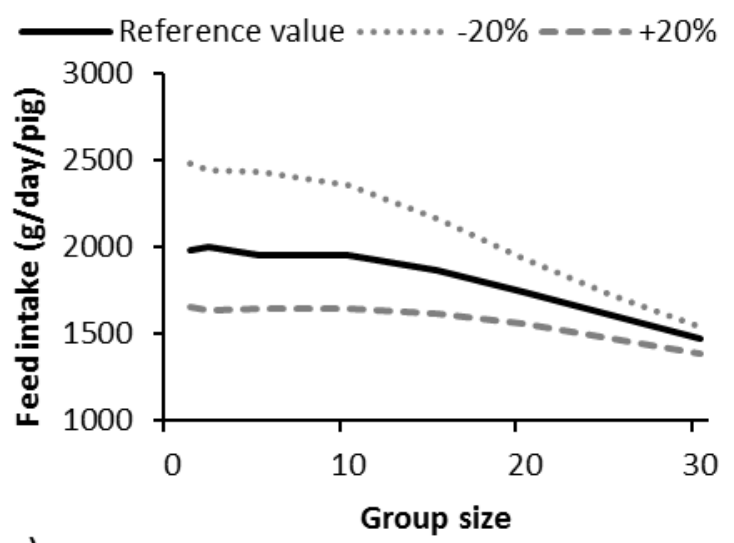

a)

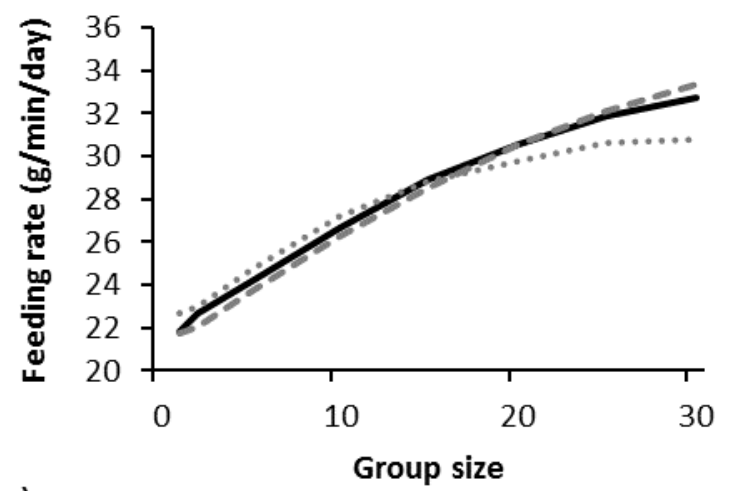

c)
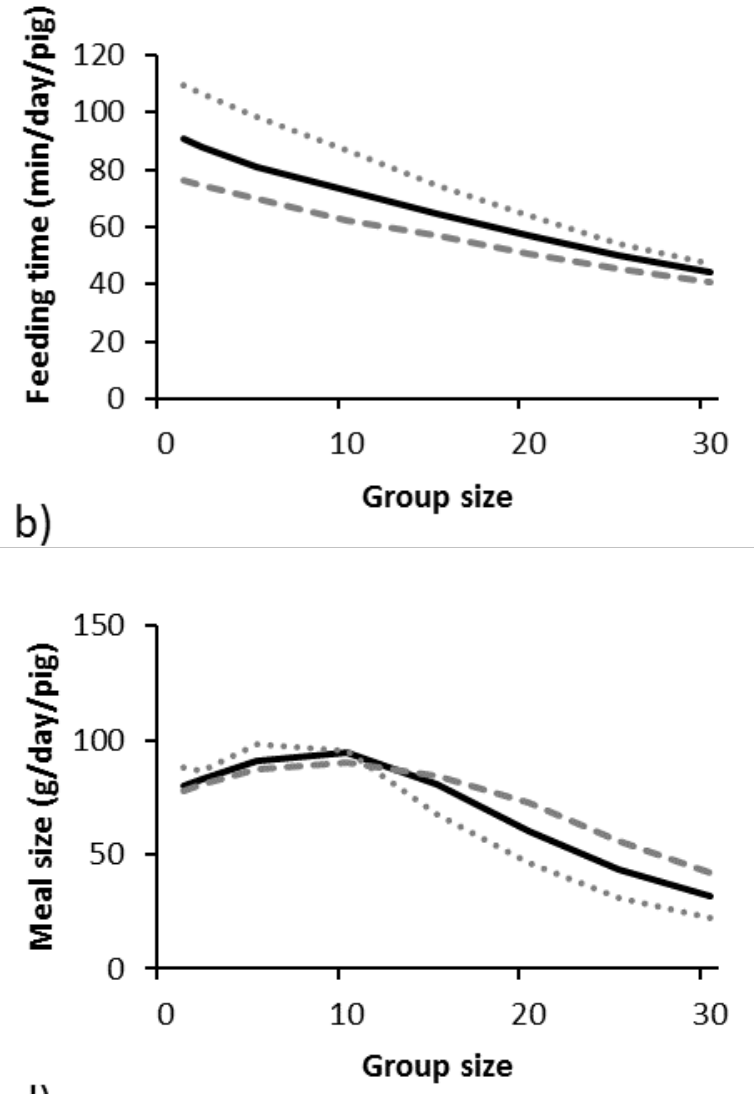

d) 


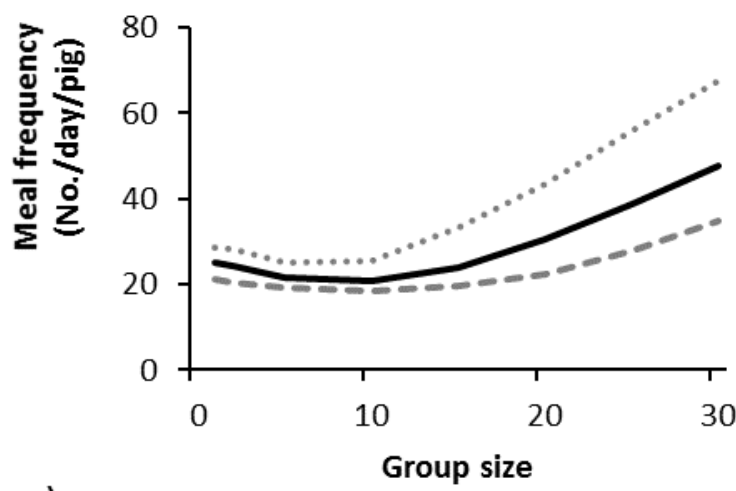

e)

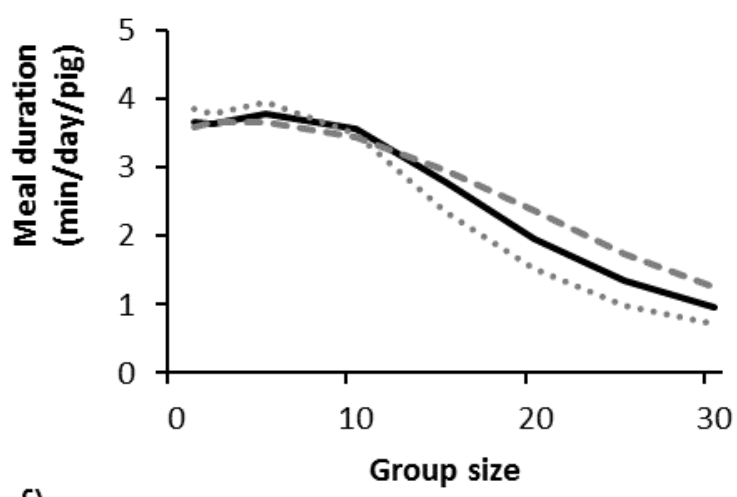

f)

Fig. A1. Sensitivity analysis of patterns of feed intake (a), feeding time (b), feeding rate (c), meal size (d), meal frequency (e) and meal duration (f) to diet energy parameter change of $20 \%$ in various group sizes. Averages are shown for 10 simulation runs per group size in scenario 4 .
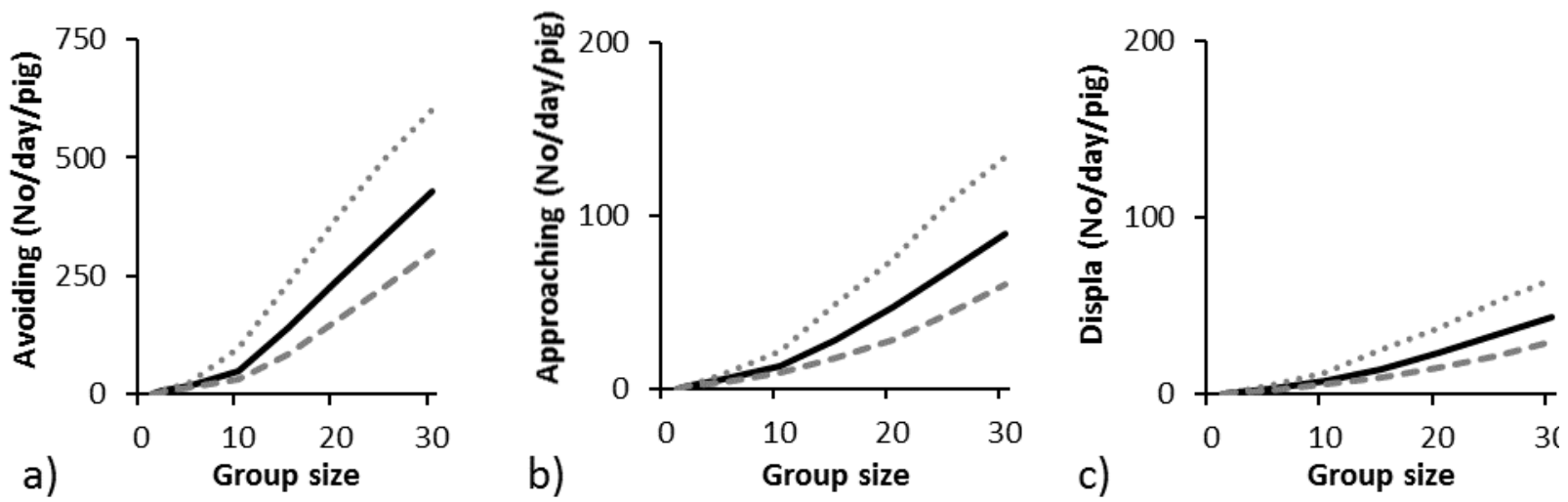

Fig. A2. Sensitivity analysis of patterns of avoiding (a), approaching (b) and displacing (c) to diet energy parameter change of $20 \%$ in various group sizes. Averages are shown for 10 simulation runs per group size in scenario 4.

\section{References}

[1] Strubbe, J. H., van Dijk, G. The temporal organization of ingestive behaviour and its interaction with regulation of energy balance. Neuroscience \& Biobehavioral Reviews. 2002,26:485-98.

[2] Clayton, D. A. Socially facilitated behavior. The Quarterly Review of Biology. 1978,53:373-92.

[3] Smith, J. M., Price, G. R. The logic of animal conflict. Nature. 1973,246:15-8.

[4] Arnott, G., Elwood, R. W. Information gathering and decision making about resource value in animal contests. Animal Behaviour. 2008,76:529-42.

[5] Smith, J. M., Parker, G. A. The logic of asymmetric contests. Animal Behaviour. 1976,24:159-75.

[6] Price, E. O. Behavioral development in animals undergoing domestication. Applied Animal Behaviour Science. 1999,65:245-71.

[7] Andersen, I. L., Nævdal, E., Bakken, M., Bøe, K. E. Aggression and group size in domesticated pigs, Sus scrofa: 'when the winner takes it all and the loser is standing small'. Animal Behaviour. 2004,68:965-75. [8] Hemsworth, P. H., Rice, M., Nash, J., Giri, K., Butler, K. L., Tilbrook, A. J., et al. Effects of group size and floor space allowance on grouped sows: Aggression, stress, skin injuries, and reproductive performancel. Journal of Animal Science. 2013,91:4953-64.

[9] Szendrő, K., Szendrő, Z., Matics, Z., Dalle Zotte, A., Odermatt, M., Radnai, I., et al. Effect of genotype, housing system and hay supplementation on performance and ear lesions of growing rabbits. Livestock Science. 2015,174: 105-12.

[10] Cornetto, T., Estevez, I., Douglass, L. W. Using artificial cover to reduce aggression and disturbances in domestic fowl. Applied Animal Behaviour Science. 2002,75:325-36.

[11] Estevez, I., Andersen, I.-L., Nævdal, E. Group size, density and social dynamics in farm animals. Applied Animal Behaviour Science. 2007,103: 185-204. 
[12] Boumans, I. J. M. M., Hofstede, G. J., Bolhuis, J. E., de Boer, I. J. M., Bokkers, E. A. M. Agent-based modelling in applied ethology: An exploratory case study of behavioural dynamics in tail biting in pigs. Applied Animal Behaviour Science. 2016,183:10-8.

[13] Asher, L., Collins, L. M., Ortiz-Pelaez, A., Drewe, J. A., Nicol, C. J., Pfeiffer, D. U. Recent advances in the analysis of behavioural organization and interpretation as indicators of animal welfare. Journal of The Royal Society Interface. 2009,6:1103-19.

[14] Nielsen, B. L., Lawrence, A. B., Whittemore, C. T. Feeding behaviour of growing pigs using single or multispace feeders. Applied Animal Behaviour Science. 1996,47:235-46.

[15] Andersen, I. L., Nævdal, E., Bøe, K. E., Bakken, M. The significance of theories in behavioural ecology for solving problems in applied ethology-Possibilities and limitations. Applied Animal Behaviour Science. 2006,97:85-104.

[16] Boumans, I. J. M. M., Bokkers, E. A. M., Hofstede, G. J., de Boer, I. J. M. Understanding feeding patterns in growing pigs by modelling growth and motivation. Applied Animal Behaviour Science. 2015,171:69-80.

[17] Boumans, I. J. M. M., de Boer, I. J. M., Hofstede, G. J., la Fleur, S. E., Bokkers, E. A. M. The importance of hormonal circadian rhythms in daily feeding patterns: An illustration with simulated pigs. Hormones and Behavior. 2017,93:82-93.

[18] Grimm, V., Railsback, S. F. Pattern-oriented modelling: a 'multi-scope' for predictive systems ecology. Philosophical Transactions of the Royal Society of London B Biological Sciences. 2012,367:298-310.

[19] Grimm, V., Revilla, E., Berger, U., Jeltsch, F., Mooij, W. M., Railsback, S. F., et al. Pattern-oriented modeling of agent-based complex systems: lessons from ecology. Science. 2005,310:987-91.

[20] Walker, N. The effects on performance and behaviour of number of growing pigs per mono-place feeder. Animal Feed Science and Technology. 1991,35:3-13.

[21] Hyun, Y., Ellis, M. Effect of group size and feeder type on growth performance and feeding patterns in growing pigs. Journal of Animal Science. 2001,79:803-10.

[22] Hyun, Y., Ellis, M. Effect of group size and feeder type on growth performance and feeding patterns in finishing pigs. Journal of Animal Science. 2002,80:568-74.

[23] Nielsen, B. L., Lawrence, A. B., Whittemore, C. T. Effect of group size on feeding behaviour, social behaviour, and performance of growing pigs using single-space feeders. Livestock Production Science. 1995, 44:73-85.

[24] De Haer, L. C. M., Merks, J. W. M. Patterns of daily food intake in growing pigs. Animal Science. 1992,54:95-104.

[25] Botermans, J. A. M., Georgsson, L., Weström, B. R., Olsson, A.-C., Svendsen, J. Effect of Feeding Environment on Performance, Injuries, Plasma Cortisol and Behaviour in Growing-finishing Pigs: Studies on Individual Pigs Housed in Groups. Acta Agriculturae Scandinavica, Section A - Animal Science. 2000,50:25062.

[26] Nielsen, B. L. On the interpretation of feeding behaviour measures and the use of feeding rate as an indicator of social constraint. Applied Animal Behaviour Science. 1999,63:79-91.

[27] Wilensky, U. Netlogo. Evaston, Illinois: Center for Connected Learning and Computer-Based Modeling, Northwestern University; 1999.

[28] Grimm, V., Berger, U., Bastiansen, F., Eliassen, S., Ginot, V., Giske, J., et al. A standard protocol for describing individual-based and agent-based models. Ecological Modelling. 2006,198:115-26.

[29] Grimm, V., Berger, U., DeAngelis, D. L., Polhill, J. G., Giske, J., Railsback, S. F. The ODD protocol: A review and first update. Ecological Modelling. 2010,221:2760-8.

[30] Boumans, I. J. M. M. A model on feeding and social interaction behaviour of pigs. Model version 3. https://www.comses. net/codebases/5628/releases/1.0.0/: CoMSES Computational Model Library; 2017.

[31] Keeling, L. J., Hurnik, J. F. Social facilitation acts more on the appetitive than the consummatory phase of feeding behaviour in domestic fowl. Animal Behaviour. 1996,52:11-5.

[32] Pedersen, L. J., Jensen, M. B., Hansen, S. W., Munksgaard, L., Ladewig, J., Matthews, L. Social isolation affects the motivation to work for food and straw in pigs as measured by operant conditioning techniques. Applied Animal Behaviour Science. 2002,77:295-309.

[33] Hemelrijk, C. K. Towards the integration of social dominance and spatial structure. Animal Behaviour. 2000,59: 1035-48.

[34] Hemelrijk, C. K. An individual-orientated model of the emergence of despotic and egalitarian societies. Proceedings of the Royal Society of London. Series B: Biological Sciences. 1999,266:361-9.

[35] Brouns, F., Edwards, S. A. Social rank and feeding behaviour of group-housed sows fed competitively or ad libitum. Applied Animal Behaviour Science. 1994,39:225-35.

[36] Hoy, S., Schamun, S., Weirich, C. Investigations on feed intake and social behaviour of fattening pigs fed at an electronic feeding station. Applied Animal Behaviour Science. 2012,139:58-64.

[37] Bolhuis, ]. E., Schouten, W. G. P., Schrama, ]. W., Wiegant, V. M. Behavioural development of pigs with different coping characteristics in barren and substrate-enriched housing conditions. Applied Animal Behaviour Science. 2005,93:213-28.

[38] Camerlink, I., Turner, S. P., Farish, M., Arnott, G. Aggressiveness as a component of fighting ability in pigs using a game-theoretical framework. Animal Behaviour. 2015,108:183-91.

[39] R Core Team. R: A language and environment for statistical computing. Vienna, Austria: R Foundation for Statistical Computing; 2015.

[40] De Haer, L. C. M., de Vries, A. G. Feed intake patterns of and feed digestibility in growing pigs housed individually or in groups. Livestock Production Science. 1993,33:277-92.

[41] Brouns, F., Edwards, S. A., English, P. R. Effect of dietary fibre and feeding system on activity and oral behaviour of group housed gilts. Applied Animal Behaviour Science. 1994,39:215-23.

[42] De Haer, L. C. M., de Vries, A. G. Effects of genotype and sex on the feed intake pattern of group housed growing pigs. Livestock Production Science. 1993,36:223-32. 
[43] Quiniou, N., Dubois, S., Noblet, J. Voluntary feed intake and feeding behaviour of group-housed growing pigs are affected by ambient temperature and body weight. Livestock Production Science. 2000,63:245-53.

[44] J ohnson, D. F., Ackroff, K. M., Collier, G. H., Plescia, L. Effects of dietary nutrients and foraging costs on meal patterns of rats. Physiology \& Behavior. 1984,33:465-71.

[45] Illius, A. W., Gordon, I. J. The allometry of food Intake in grazing ruminants. Journal of Animal Ecology. 1987,56:989-99.

[46] Collins, L. M., Asher, L., Pfeiffer, D. U., Browne, W. J., Nicol, C. J. Clustering and synchrony in laying hens: The effect of environmental resources on social dynamics. Applied Animal Behaviour Science. 2011,129:43-53. [47] Jachowski, D. S., Singh, N. J. Toward a mechanistic understanding of animal migration: incorporating physiological measurements in the study of animal movement. Conservation Physiology. 2015,3.

[48] Boumans, I. J. M. M. A model on feeding and social interaction behaviour of pigs. Model version 4. https://www.comses. net/codebases/5628/releases/1.1.0/: CoMSES Computational Model Library; 2018. 